\title{
A Further Study of a CISK Mode Unaffected by Surface Friction
}

\author{
By Masanori Yamasaki \\ Meteorological Research Institute, Tokyo \\ (Manuscript received 23 October 1978, in revised form 16 February 1979)
}

\begin{abstract}
As a continuation of a previous study (Yamasaki, 1975), several numerical experiments are performed to investigate the properties of a CISK mode which is not essentially affected by surface friction. A set of equations used for time integrations includes equations for cloud water and rainwater with parameterized cloud physical processes such as autoconversion, collection and so on. The horizontal grid size is taken to be $200 \mathrm{~m}$ in the convective area so that individual cumulus clouds may be properly described. For the save of computational time we adopt an initial condition such that formations of cumulus clouds are limited in a small area with a scale of only several tens of kilometers. The depth of the conditionally unstable layer is taken to be shallow so that the vorticity of the disturbance, which develops through its interaction with cumulus clouds, does not become large enough to cause appreciable frictional convergence.

Numerical experiments indicate that the advection of momentum as well as the pressure gradient force are important terms in the equation of horizontal motion. The convective transport of momentum acts to suppress rapid intensification of the meridional circulation which is caused by the temperature gradient due to collective effects of convective heating. The Coriolis force has only modifying effects on the growth and structure of the disturbance. Rainfalls in the convective area do not occur randomly but systematically to some extent. In particular, outward propagations of rainfall area are notably found. It is unlikely that cumulus clouds are successively formed when the autoconversion from cloud water to rainwater is not taken into account. It seems that the evaporation and drag force of rainwater play an essential role in the CISK mode under consideration.

The statistical effects of cumulus clouds on the large-scale heat and water vapor budgets as well as the behaviors of individual cumulus clouds are also discussed.
\end{abstract}

\section{Introduction}

The term 'CISK' has been used as an abbreviation of the 'Conditional Instability of the Second Kind' that expresses an instability of the atmosphere in which a disturbance develops through its interaction with cumulus convection in the conditionally unstable stratification. The most typical manifestations of such an instability are the tropical cyclone and the so-called easterly wave in the tropics. So far many dynamical studies have been made in attempts to explain these phenomena. In the dynamical models which include parameterized convection, several modes induced by the CISK mechanism have been found.

The first mode is a relatively small-scale quasi- geostrophic (or quasi-balanced) mode whose preferred horizontal scale is generally less than several hundred kilometers. This mode was found by Ooyama (1964) in his attempt to explain the horizontal and time scales of the tropical cyclone. We shall call this mode 'tropical cyclone mode', which will be abbreviated as TC mode. The properties of this mode have been intensively studied by the use of linear (or quasi-linear) models (Charney and Eliassen, 1964; Ogura, 1964; Syono and Yamasaki, 1966; Yamasaki, 1969; Rosenthal and Koss, 1968; Chang and Williams, 1974; Wada, 1977) and by numerical experiments with non-linear models (Ogura, 1964; Ooyama, 1969; Yamasaki, 1968a, b, c; Sundqvist, $1970 \mathrm{a}, \mathrm{b}$; and others). One of important features of TC mode is that frictional convergence is 
pronounced. It is also known that surface friction is indispensable to the instability of TC mode (Ooyama, 1964; Syono and Yamasaki, 1966).

In connection with the easterly wave in the tropical troposphere, two kinds of CISK modes may exist (Yamasaki, 1969, 1971). One is Rossby wave destabilized by the combined effect of convective heating, vertical shear of the basic flow (such as trade easterlies) and surface friction. The other is a baroclinic unstable wave greatly modified by convective heating and surface friction. These modes were named $E$ mode (easterly wave without steering current) and $E S$ mode (easterly wave with steering current), respectively. The properties of these modes were also studied by Murakami (1972) in his study of tropical disturbances and by Tokioka (1973) and Gambo (1976) in their studies of the so-called mediumscale disturbance in the middle latitudes.

A possibility was also suggested that planetaryscale Rossby waves could be destabilized by convective heating (Yamasaki, 1969). It was shown that the vertical structure of this mode is similar to that of Yanai and Maruyama (1966)'s wave observed in the lower stratosphere of the equatorial region. The three-dimensional feature of this mode was studied by Hayashi (1970, 1971), Yamasaki (1971), Murakami (1972) and Lindzen (1974). In these studies, instability theories of Rossby waves and the mixed Rossby gravity wave (Matsuno, 1966) were developed. Hayashi (1970) also found that Kelvin wave could be unstable. When convective heating is relatively strong, these modes could be destabilized without surface friction (Yamasaki, 1969). The CISK of this type was named 'Wave CISK' by Lindzen (1974). Stark (1976) discussed that Wave CISK was not found in a model which included a 'modified' version of Arakawa and Schubert (1974)'s parameterized convection.

In a dynamical study of the meso-scale disturbance, Matsumoto and Ninomiya (1969) found an unstable wave which behaved like gravity waves when momentum transport due to cumulus convection was taken into consideration. Another type of gravity mode CISK may be the spiral rainband which was simulated in numerical experiments of tropical cyclones by Anthes et al. (1971), Anthes (1972), Kurihara and Tuleya (1974) and Mathur (1975). They suggested that the rainbands obtained in their experiments were internal gravity waves destabilized by convective heating. The instability of this type is similar to that of gravity waves discussed by Syono and
Yamasaki (1966).

In these models referred above, the effects of cumulus convection have been parameterized in terms of large-scale variables. Therefore, the extent to which these unstable modes can explain observed phenomena depends on the validity of cumulus parameterization used. In a previous paper (Yamasaki, 1975) another approach to understanding of CISK was attempted. That is, a numerical model was proposed in which the effects of cumulus conver ion were not parameterized but individual convective clouds were treated. Since neither basic flow nor $\beta$-effect (latitudinal variation of the Coriolis parameter) were taken into account, it was expected that the model was appropriate for describing $T C$ mode and gravity mode CISK. By introducing a symmetric assumption in the Cartesian coordinates, a numerical experiment was performed with the intention of simulating $T C$ mode. Contrary to such an intention, a disturbance which developed in that experiment was not $T C$ mode but a new kind of unstable mode. A significant difference between this mode and TC mode is that frictional convergence is not noticeable in this mode.

A CISK mode obtained in a numerical experiment of Yamasaki (1977a) was similar to $T C$ mode in many respects. However, this mode, which is referred to as $A F$ mode, was different from $T C$ mode, particularly with respect to the effect of surface friction on the instability. As mentioned before, $T C$ mode is reduced to a neutral mode in the absence of surface friction. On the contrary, as shown in Yamasaki (1977b), $A F$ mode becomes a different kind of unstable mode similar to that obtained in Yamasaki (1975). One possible interpretation is that $A F$ mode is a superposition of TC mode and NF mode, where NF mode is defined as a CISK mode whose stability properties are not essentially affected by surface friction. Results obtained in Yamasaki $(1975,1977 \mathrm{a}, \mathrm{b})$ are consistent with this interpretation as follows. If surface friction does not exist (Yamasaki, 1977b), NF mode predominates because TC mode is neutral. Even when surface friction exists, NF mode may predominate if the vorticity of the disturbance is weak, as in the case of Yamasaki (1975). When the disturbance becomes strong, TC mode with pronounced frictional convergence predominates (Yamasaki, 1977a). In this case AF mode becomes similar to TC mode. It was also suggested in Yamasaki (1977b) that tropical cyclones simulated by Anthes et al. (1971) and Kurihara and Tuleya (1974) 
might be similar to AF mode rather than TC mode.

In view of a possibility that NF mode may play an important role in weak disturbances and in the early stages of tropical cyclone development, it may be interesting to study the properties of NF mode in more detail. The present paper deals with this problem. As mentioned above, the instability of NF mode is, by its definition, essentially unaffected by surface friction (, although it is affected indirectly through interaction with TC mode). In this respect it should be remarked that the gravity mode CISK probably has the same property. A main difference between NF mode and the gravity mode CISK is that the latter is a propagating mode.

\section{Model}

The model used in this study is the same as that in Yamasaki (1975). The numerical experiment described in that paper will be referred to as Case (C). In the present study several numerical experiments are performed by changing physical parameters such as the coefficient concerning surface friction, the Coriolis parameter, the coefficient of autoconversion from cloud water to rainwater, initial conditions and the geometry of the disturbance. ${ }^{*}$ A brief description of the model is given below. For further details readers are referred to Yamasaki (1975).

A set of equations used may be written, using the Cartesian coordinates $(x, y, z)$, as follows:

$$
\begin{aligned}
& \frac{d u}{d t}-f v=-c_{p} \theta_{0} \frac{\partial \pi}{\partial x}+F_{H}(u)+F_{V}(u) \\
& \frac{d v}{d t}+f u=F_{H}(v)+F_{V}(v) \\
& \frac{d w}{d t}=-c_{p} \theta_{0} \frac{\partial \pi}{\partial z}+g\left(\frac{\theta}{\theta_{0}}+0.608 q_{v}-q_{c}-q_{r}\right) \\
& +F_{H}(w)+F_{V}(w) \\
& \frac{\partial\left(\rho_{0} u\right)}{\partial x}+\frac{\partial\left(\rho_{0} w\right)}{\partial z}=0 \\
& \frac{d \theta}{d t}+w \frac{\partial \theta_{0}}{\partial z}=\frac{L}{c_{p} \pi_{0}}\left(C-E_{r}\right) \\
& +F_{H}(\theta)+F_{V}(\theta) \\
& \frac{d q_{v}}{d t}+w \frac{\partial q_{v 0}}{\partial z}=-C+E_{r}+F_{H}\left(q_{v}\right) \\
& +F_{V}\left(q_{v}\right)
\end{aligned}
$$

* In this paper, the term 'disturbance' is used to express the 'large-scale' disturbance induced by collective effects of cumulus clouds, where 'largescale' means scales larger than about one hundred kilometers.

$$
\begin{aligned}
& \frac{d q_{c}}{d t}=C-A-C_{0}+F_{H}\left(q_{c}\right)+F_{V}\left(q_{c}\right) \\
& \frac{d q_{r}}{d t}=A+C_{0}-E_{r}+\frac{1}{\rho_{0}} \frac{\partial}{\partial z}\left(\rho_{0} q_{r} V_{T}\right)
\end{aligned}
$$

where

$$
\begin{aligned}
& \frac{d}{d t}=\frac{\partial}{\partial t}+u \frac{\partial}{\partial x}+w \frac{\partial}{\partial z} \\
& F_{H}(Y)=K_{H} \frac{\partial^{2} Y}{\partial x^{2}} \\
& F_{V}(Y)=\frac{1}{\rho_{0}} \frac{\partial}{\partial z}\left(\rho_{0} K_{V} \frac{\partial Y}{\partial z}\right)
\end{aligned}
$$

As indicated by these equations, all dependent variables are assumed to be uniform in the $y$ direction. The use of a two-dimensional model is a reasonable step toward a realistic threedimensional model, which is, however, difficult to be used at the present time. The dependent variables are $u=x$-component of velocity, $v=$ $y$-component of velocity, $w=$ vertical velocity, $\pi=$ non-dimensional pressure deviation from the basic state, $\theta=$ potential temperature deviation, $q_{v}=$ mixing ratio deviation of water vapor, $q_{c}=$ mixing ratio of cloud water and $q_{r}=$ mixing ratio of rain water. Other notations are $Y=$ any dependent variable, $f=$ Coriolis parameter (taken to be $\left.5 \times 10^{-5} \mathrm{sec}^{-1}\right), c_{p}=$ specific heat of dry air at constant pressure, $L=$ latent heat of condensation, $g=$ acceleration of gravity, $K_{H}=$ horizontal eddy diffusion coefficient (assumed to be $100 \mathrm{~m}^{2} \mathrm{sec}^{-1}$ ) and $K_{V}=$ vertical eddy diffusion coefficient (assumed to be $10 \mathrm{~m}^{2} \mathrm{sec}^{-1}$ ). The variables $\theta_{0}, \pi_{0}, q_{v 0}$ and $\rho_{0}$ are, respectively, potential temperature, non-dimensional pressure, mixing ratio of water vapor and density of the basic state, which are functions of $z$ only.

These equations are similar to those used in many numerical experiments of the isolated convective cloud without ice phase (e.g., Murray and Koenig, 1972; Wilhelmson and Ogura, 1972). Main difference is that the Coriolis force and surface friction are taken into account. Surface friction is included in the form of the lower boundary condition, which may be written as follows:

$$
\left.\begin{array}{l}
\rho_{0} K_{V} \frac{\partial u}{\partial z}=\rho_{0} c_{D} u\left(u^{2}+v^{2}\right)^{1 / 2} \\
\rho_{0} K_{V} \frac{\partial v}{\partial z}=\rho_{0} c_{D} v\left(u^{2}+v^{2}\right)^{1 / 2}
\end{array}\right\} \text { at } z=0
$$

where $c_{D}$ is the drag coefficient.

The rate of condensation (or evaporation of cloud water) $C$ is determined under the assump- 
tions that the air does not become supersaturated and that cloud water does not exist in the unsaturated air. The rate of autoconversion from cloud water to rainwater $A$, collection $C_{0}$, evaporation of rainwater $E_{r}$ and terminal velocity of volume-median raindrops (positive downward) $V_{T}$ are assumed to be as follows (in cgs units):

$$
\begin{aligned}
& A=\alpha\left(q_{c}-\beta / \rho_{0}\right) \geq 0 \\
& C_{0}=929 q_{c}\left(\rho_{0} q_{r}\right)^{7 / 8} \\
& E_{r}=4.32\left\{q_{s}-\left(q_{v 0}+q_{v}\right)\right\}\left(\rho_{0} q_{r}\right)^{0.65} \geq 0 \\
& V_{T}=2.9 \times 10^{3}\left(\rho_{0} q_{r}\right)^{1 / 8}
\end{aligned}
$$

where $\alpha$ is Kessler (1969)'s autoconversion rate, $\beta$ is a threshold value for autoconversion and $q_{S}$ is the saturation mixing ratio.

It is assumed that $w, \theta, q_{v}$ and $q_{c}$ are symmetric with respect to $x=0$, and $u$ and $v$ are antisymmetric. This assumption means that we consider a stationary (non-propagating) CISK mode. The outer boundary is placed at $x=$ $500 \mathrm{~km}$, and the same conditions are imposed there. At the earth's surface we assume that the temperature and the mixing ratio of water vapor are kept constant. It may be considered that this assumption does not alter essential features of CISK mode under consideration. We impose the upper boundary at $z=5.4 \mathrm{~km}$ where the potential temperature and the mixing ratio of water vapor are assumed to be constant.

The initial conditions taken for Case (C) in Yamasaki (1975) were as follows: (1) The atmosphere is at rest and no liquid water exist. (2) The lapse rate of the basic state temperature is $8^{\circ} \mathrm{K} /$ $\mathrm{km}$ below $z=1 \mathrm{~km}, 6^{\circ} \mathrm{K} / \mathrm{km}$ for $1<z<3 \mathrm{~km}$, and it decreases linearly above, becoming zero above $4.6 \mathrm{~km}$. Five temperature perturbations are given so that convective clouds may be formed. These perturbations are centered at $x=$ $0,4,8,12$ and $16 \mathrm{~km}$, and at a height of $1.5 \mathrm{~km}$. The maximum temperature deviation is $0.5 \mathrm{~K}$. (3) The relative humidity is a function of $z$ only, which is given in Table 1 as HA.

Equations (1)-(8) are numerically integrated with the use of a two-dimensional grid. The horizontal mesh size is taken to be $200 \mathrm{~m}$ for $x \leq 20 \mathrm{~km}$. Larger and variable mesh sizes are used for the outer domain. The number of grid points in the $x$-direction is 140 . The vertical grid size is $300 \mathrm{~m}$, and thus the number of layers is 18. A time increment of 20 seconds satisfies the computational stability.

As mentioned before, several numerical experiments are performed by changing physical parameters and initial conditions. In the follow- ing section the objective of each experiment is mentioned with specification of experimental parameters, and results are presented.

\section{Numerical experiments}

\subsection{Case (CD)}

As mentioned in section 1, frictional convergence was not noticeable in Case (C) because the vorticity of the disturbance did not become large (Yamasaki, 1975). This means that surface friction did not play an important role in Case (C). In order to make sure that this is the case, a numerical experiment (referred to as Case CD) is performed with $c_{D}=0$ in (9), other conditions being the same as those in Case (C).

We shall compare the rainfall intensity at the surface in Case (CD) with that in Case (C). For convenience, Fig. 9 in Yamasaki (1975) is reproduced in Fig. 1 and the result for Case (CD)

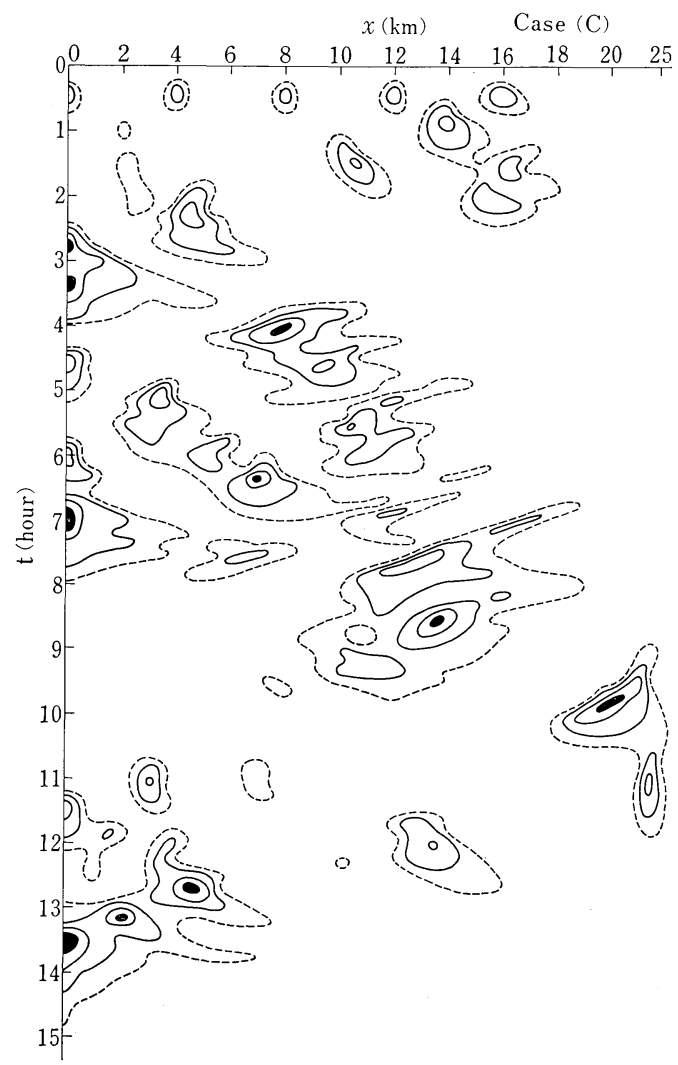

Fig. 1 Rainfall intensity at the surface for Case (C) as a function of $x$ and $t$. The dashed line indicates an intensity of $0.1 \mathrm{~mm}$ per 10 minutes. The solid lines are drawn for intensities of 1,5 and $10 \mathrm{~mm}$ per 10 minutes. The intensities larger than $10 \mathrm{~mm}$ are shaded. 


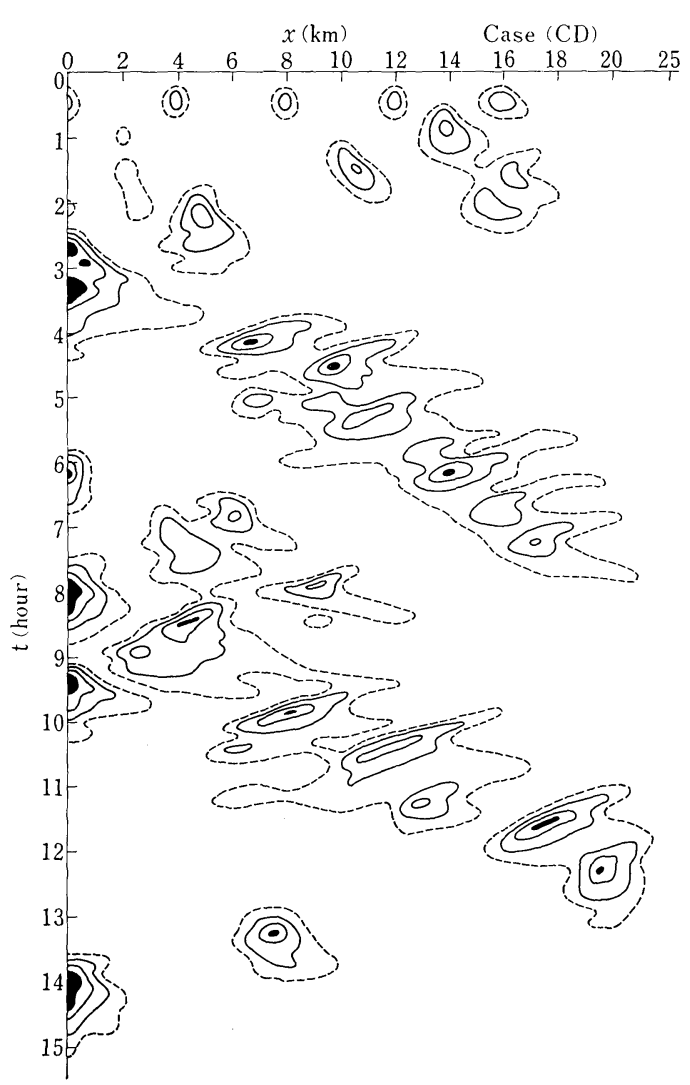

Fig. 2 Rainfall intensity at the surface for Case (CD) in which surface friction is not included.

is in Fig. 2. In these figures the rainfall intensities are shown as functions of $x$ and time. The dashed lines indicate that the intensity is $0.1 \mathrm{~mm}$ per 10 minutes. The solid lines are drawn for intensities of 1,5 and $10 \mathrm{~mm}$ per 10 minutes. The areas where the intensity exceeds $10 \mathrm{~mm}$ are shaded. It can be seen that gross features of the rainfall pattern in Case (CD) are very similar to those in Case (C). The duration time of rainfall is about 15 hours in both cases. Individual rainfalls, however, show some differences after 4 hours. In Case (CD) two outward propagations of rainfall area, which start at the disturbance center $(x=0)$ around 3 hours and 8 . hours, are more distinct. In Case (C) these propagations interact somewhat complicatedly.

Comparison of the rainfall patterns suggests that the behavior of the large-scale circulation in Case (CD) is similar to that in Case (C). As an example, the time changes of the maximum and minimum values of $v$ are shown in Fig. 3 (indicated by $\mathrm{C}$ and $\mathrm{CD}$ ). The maximum value

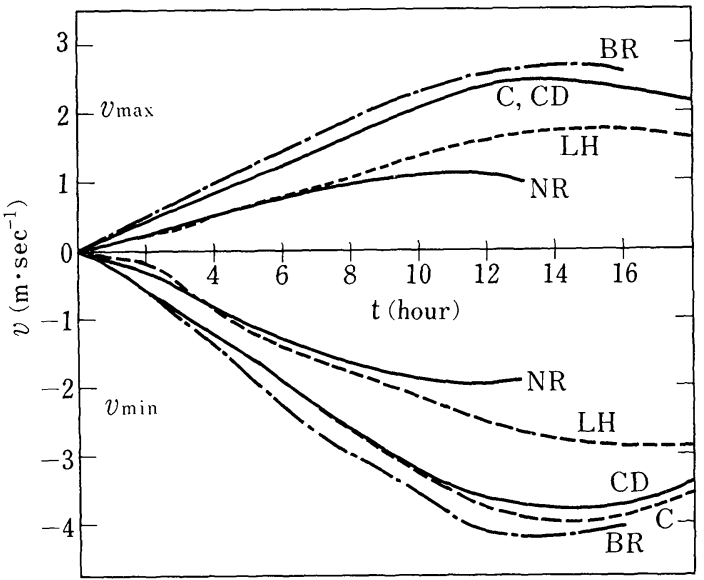

Fig. 3 Time changes of the maximum and minimum values of $v$ for various cases.

in Case (CD) is almost the same as that in Case (C).

\subsection{Case (F)}

It is well known that the Coriolis force is essential to the instability of TC mode (Ooyama, 1964). This is closely related to the important role of surface friction in TC mode because the Coriolis force is indispensable to produce frictional convergence. In the case of NF mode in which surface friction is not important, it can be inferred that the Coriolis force is not necessary for its instability, although the structure as well as the growth rate are modified. In order to confirm this, a numerical experiment, referred to as Case (F), is performed with $f=0$, other conditions being the same as those in Case (CD).

Fig. 4 shows the rainfall intensity at the surface. In this case rainfalls persist for 18 hours, which is somewhat longer than in Case (CD). This is due to stronger meridional circulation in Case (F). Fig. 5 shows the time changes of maximum velocity of $u$ averaged for $20<x<$ $30 \mathrm{~km}$ or $30<x<40 \mathrm{~km}$. It is seen that the Coriolis force has the suppressing effect in NF mode. In Case (CD) the Coriolis effect becomes large in the later stages, and thus the meridional circulation weakens more rapidly than in Case (F).

These results suggest that the advection of the momentum as well as the pressure gradient force are important terms to determine the meridional circulation in NF mode. This problem will be discussed later.

\subsection{Case (NR)}

In the following, we shall investigate the role 


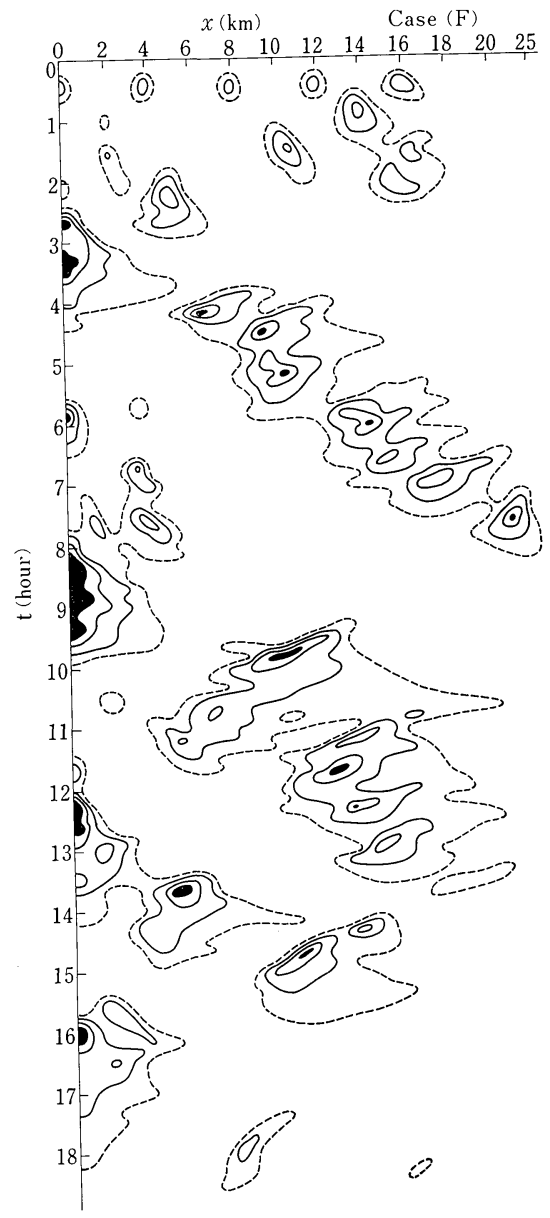

Fig. 4 Rainfall intensity at the surface for Case (F) in which neither surface friction nor the Coriolis force are not included. The scale of the abscissa is somewhat different from that of Fig. 2.

of rainwater in NF mode. It is well known that the drag force and evaporation of rainwater are important factors to produce a new cloud in the neighborhood of the original cloud (Takeda, 1971; Wilhelmson and Ogura, 1972). It is also known that non-precipitating clouds reach a quasisteady state unless the spacing of clouds is close enough to interact each other (Ogura and Takahashi, 1971). These results have been obtained for the case in which larger-scale convergence does not exist. In order to study the role of rainwater in the presence of larger-scale convergence, a numerical experiment is carried out by setting autoconversion coefficient $\alpha=0$ in (10). Other conditions are the same as those in Case (C).

Fig. 6 shows the vertical cross sections of $q_{c}$

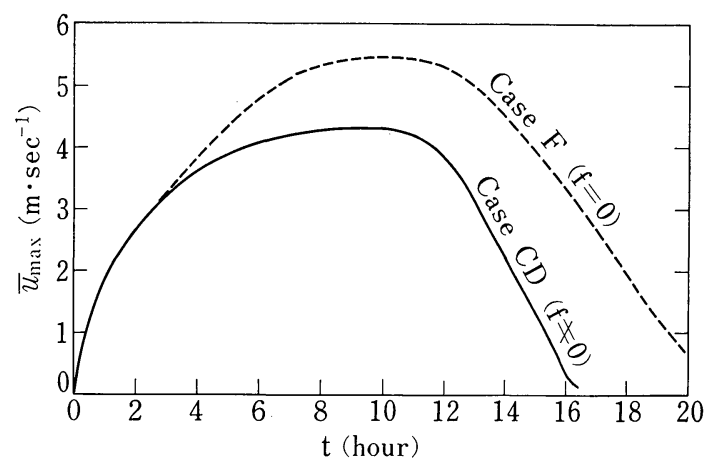

Fig. 5 Time changes of the maximum velocity of the large-scale outflow at upper levels for Case (CD) and Case (F).

(mixing ratio of cloud water) at some selected times. The solid lines are drawn for $q_{c}=0,0.3$, $0.6,1.0,2.0,3.0, \ldots \mathrm{g} / \mathrm{kg}$. The numerals indicate extreme values (units: $0.1 \mathrm{~g} / \mathrm{kg}$ ). Clouds which grow into cumulus clouds are named. At $t=40$ minutes we can see three cumulus clouds $F, G$ and $H$ in addition to those five clouds in the upper layer which are formed from initially given five perturbations. At $t=150$ minutes, clouds $H$ and $J_{1}$ are decaying, and cloud $J_{2}$ is growing. After this time, cumulus clouds are formed only near the disturbance center $(x=0)$.

In order to see the time change of cloud formation more clearly, we show $q_{c}$ at $z=1.2 \mathrm{~km}$ as a function of $x$ and time in Fig. 7. The dashed lines indicate $q_{c}=0$ and the solid lines are drawn every $0.2 \mathrm{~g} / \mathrm{kg}$. Only clouds which grow into cumulus clouds are named. In general, low-level clouds which do not grow into cumulus clouds propagate outward. This figure also shows that the number of cumulus clouds decreases with time. After 5 hours there exists only one cumulus cloud at the disturbance center. The cloud at the center remains quasi-steady until 12 hours, with oscillations of maximum mixing ratio and its location. It is worthy mentioning that this cloud is different from those simulated by many cloud experiments in the past. In the present case the outflowing air in the upper layer does not descend in the neighborhood of the cloud but go outward far away. In other words, the horizontal scale of the meridional circulation is not cloud-scale.

It may be concluded from these figures that the autoconversion process is essential to producing a number of cumulus clouds in NF mode through the drag force and evaporation of rainwater. The rainwater plays an important role in 

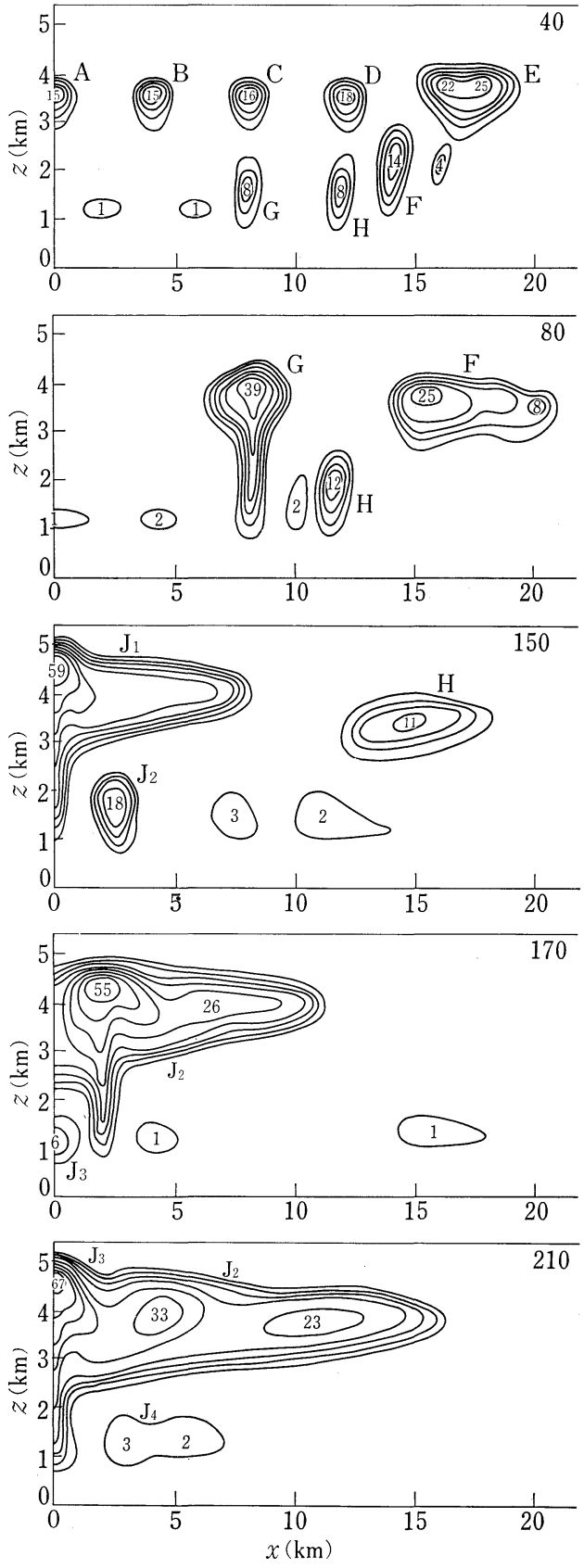

Fig. 6 Vertical cross sections of the cloud water mixing ratio at five selected times for Case (NR) in which rainwater is not produced. The numerals in clouds indicate extreme values (units, $0.1 \mathrm{~g} / \mathrm{kg}$ ). The time is indicated by numerals in the upper right corner in units of minutes.

the successive formation of convective clouds even when larger-scale convergence exists.

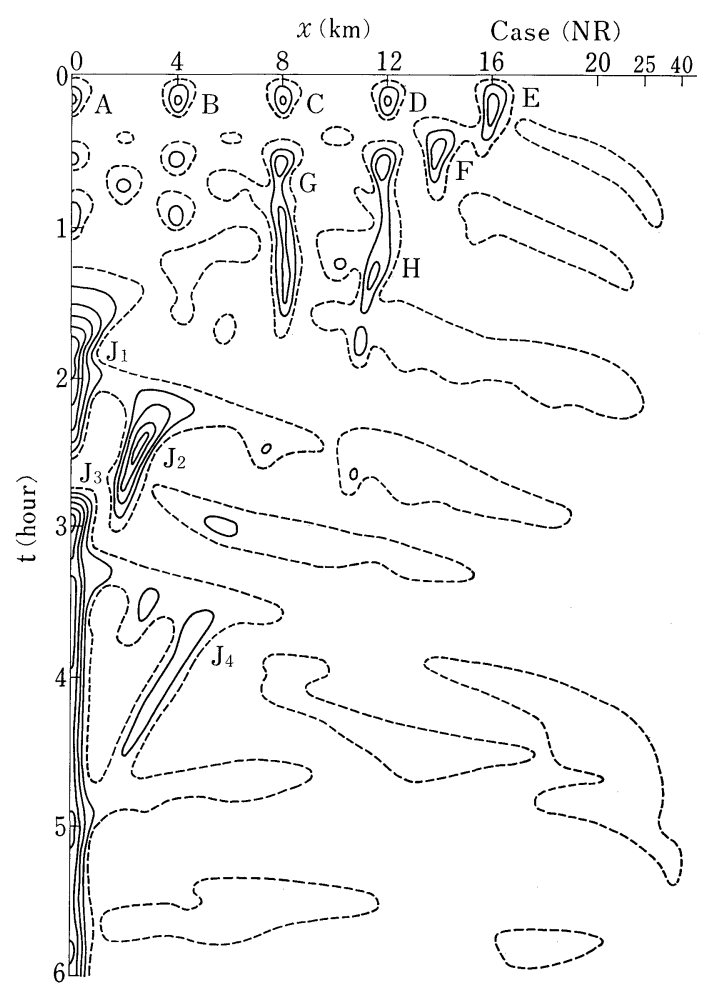

Fig. 7 Cloud water mixing ratio at a height of $1.2 \mathrm{~km}$ as a function of $x$ and $t$ for Case (NR). The solid lines are drawn every $0.2 \mathrm{~g} / \mathrm{kg}$.

\subsection{Case (BR)}

A parameterized formula of autoconversion rate was also proposed by Berry (1968). Following Wilhelmson and Ogura (1972), the autoconversion rate is given by

$$
A=b_{1} \rho_{0} q_{c}{ }^{2} /\left(1+b_{2} / \rho q_{c}\right)
$$

where $b_{1}=10^{4} / 3, \quad b_{2}=7.32 \times 10^{-9} N_{b} / D_{b}, \quad N_{b}=$ early number concentration of drops at the cloud base and $D_{b}=$ relative spectrum dispersion of cloud droplets. In Case (BR) we use (14) instead of (10). We use $N_{b}=50 \mathrm{~cm}^{-3}$ and $D_{b}=0.366$, which are considered to be typical for the maritime cloud. This case should be compared with Case (C). Fig. 8 shows the rainfall intensity at the surface. Comparison with Fig. 1 reveals that gross features of rainfalls are similar, although the propagation of rainfalls is more systematic in Case (BR) than in Case (C). In the case of Berry's parameterization, autoconversion takes place even for small amount of cloud water. On the other hand, there exists a threshold value for autoconversion in Kessler's. However, once some amount of rainwater is produced, the collection 


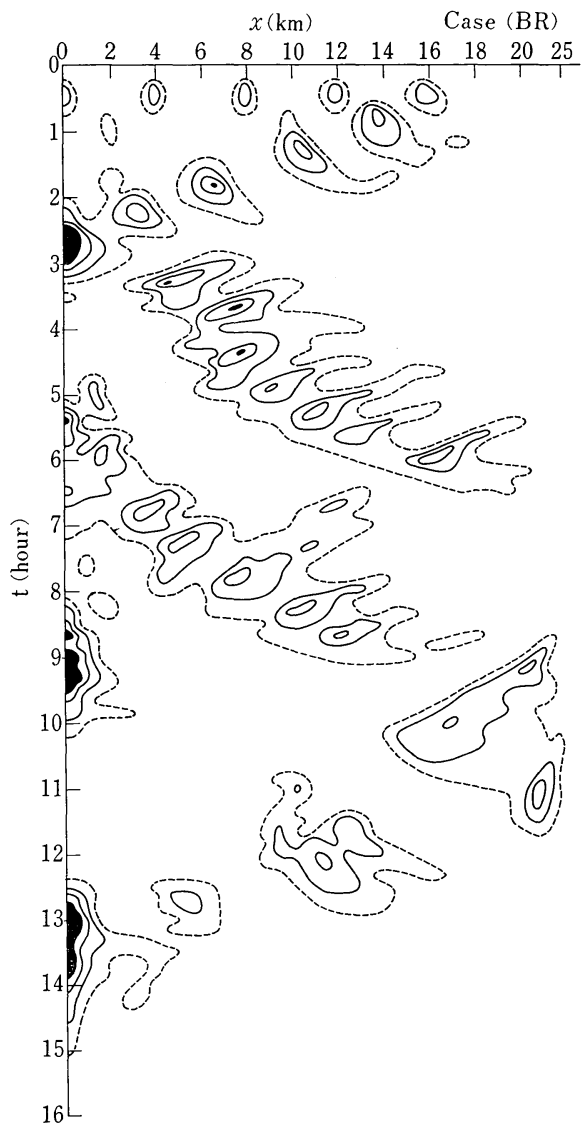

Fig. 8 Rainfall intensity at the surface for Case (BR) in which Berry (1968)'s parameterization is used.

process becomes dominant. Thus both parameterizations do not make significant differences.

The time changes of the maximum and minimum values of $v$ are shown in Fig. 3. It is found that essentially the same result as Case (C) is obtained.

\subsection{Case $(\mathrm{LH})$}

In the following three cases, we adopt different initial conditions. In Case (LH) we choose the initial relative humidity as (HB) shown in Table 1. Compared with (HA), the relative humidity is lower by $1 \sim 3 \%$ in the lower layer. Other conditions are the same as those for Case (C). The rainfall pattern is shown in Fig. 9. As expected, the rainfall is weaker in Case $(\mathrm{LH})$ than in Case (C). It should be noted that four of the first clouds due to the initially given five perturbations do not cause appreciable rainfalls. However, new precipitating clouds are formed near the center after 1 hour, and subsequent clouds are formed
Table 1. Initial relative humidity at each level.

\begin{tabular}{|c|c|c|c|}
\hline$z(\mathrm{~km})$ & $\mathrm{HA}$ & $\mathrm{HB}$ & $\mathrm{HC}$ \\
\hline 5.4 & \multicolumn{3}{|c|}{50} \\
\hline 5.1 & \multicolumn{3}{|c|}{56} \\
\hline 4.8 & \multicolumn{3}{|c|}{63} \\
\hline 4.5 & \multicolumn{3}{|c|}{71} \\
\hline 4.2 & \multicolumn{3}{|c|}{78} \\
\hline 3.9 & \multicolumn{3}{|c|}{84} \\
\hline 3.6 & \multicolumn{3}{|c|}{90} \\
\hline 3.3 & \multicolumn{3}{|c|}{95} \\
\hline 3.0 & \multicolumn{3}{|c|}{98} \\
\hline 2.7 & 100 & \multicolumn{2}{|c|}{98} \\
\hline 2.4 & 100 & \multicolumn{2}{|c|}{98} \\
\hline 2.1 & 100 & \multicolumn{2}{|c|}{98} \\
\hline 1.8 & 100 & \multicolumn{2}{|c|}{98} \\
\hline 1.5 & 100 & \multicolumn{2}{|c|}{98} \\
\hline 1.2 & 100 & \multicolumn{2}{|c|}{97} \\
\hline 0.9 & 97 & \multicolumn{2}{|c|}{95} \\
\hline 0.6 & 90 & \multicolumn{2}{|c|}{89} \\
\hline 0.3 & 84 & 83 & 81 \\
\hline 0.0 & 78 & 78 & 73 \\
\hline
\end{tabular}

one after another. Although outward propagating rainfalls are not so continuous as in Case (C), outward propagations are still clearly found.

The time changes of the maximum and minimum values of $v$ are shown in Fig. 3. As suggested from Figs. 9 and 1, meridional circulation is weaker in Case (LH) than in Case (C). Therefore, $v$ is also weaker.

\subsection{Case (FC)}

In the numerical experiments described thus far, several buoyancy perturbations have been imposed in the very humid atmosphere so that the large-scale motion as well as convective motion may take place. The humid initial condition may be considered as a result of preexisting large-scale convergence. One of more realistic initial conditions may be such that preexisting large-scale vorticity field produces frictional convergence and it makes the atmosphere humid. In this case, convective clouds may be initiated by small-scale motions which occur for some reason in the large-scale frictional convergence field. In order to simulate such a process, a numerical experiment (Case FC) is performed by assuming that the $y$-component of the velocity $v$ exists initially. The horizontal profile is shown in Fig. 10. The velocity is assumed to be independent of height and its maximum veloc- 


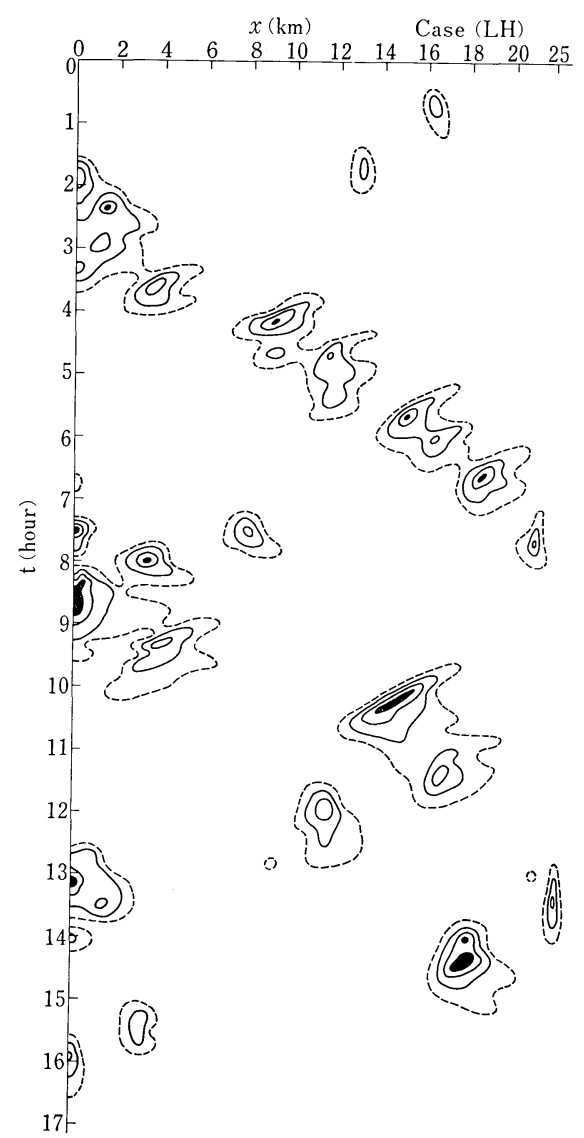

Fig. 9 Rainfall intensity at the surface for Case (LH) in which the initial relative humidity is taken to be somewhat lower.

ity is $10 \mathrm{~m} \cdot \mathrm{sec}^{-1}$, located at $x=20 \mathrm{~km}$. In order to save computational time, the initial humidity is assumed to be still humid, as Case (HB). In addition, the Coriolis parameter $f$ is chosen as $10^{-4} \mathrm{sec}^{-1}$. A larger value of $f$ produces stronger frictional convergence, and therefore it takes less time for the atmosphere to become saturated. The values of other parameters are taken to be the same as those for Case (C).

As mentioned before, large-scale ascending motion due to frictional convergence is not exactly uniform, but small-scale irregular motions appear particularly after large-scale condensation occurs. In order to see how clouds are formed, vertical cross sections of the mixing ratio of cloud water are shown in Fig. 11. We can see five convective clouds at low levels at $t=320$ minutes. These clouds have developed from lowlevel stratiform clouds which are produced by large-scale condensation. Among these clouds,

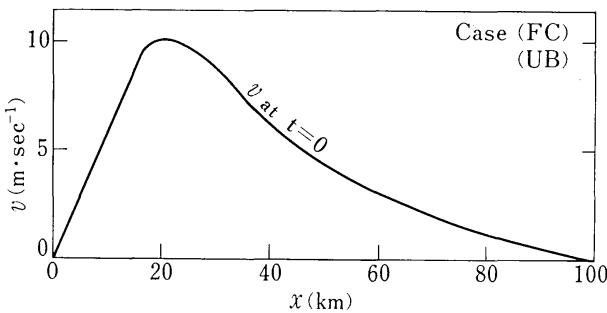

Fig. 10 The initial horizontal profile of $v$ used in Case (FC) and Case (UB) in which buoyancy perturbations are not given initially.

only cloud A grows and the other clouds disappear at $350 \mathrm{~min}$. The combined effects of the downdraft associated with cloud $\mathrm{A}$ and frictional convergence produce new clouds. The large-scale meridional circulation is intensified by the effects of these clouds. Then frictional convergence ceases to play an important role. The process of cloud formation becomes quite similar to that in the previous cases. Fig. 12 shows the rainfall intensity. It is seen that the duration time of rainfalls is about 12 hours, which is comparable to those for other cases. The rain area propagates outward also in this case. It is certain that the instability mechanism in Case (FC) is the same as that in other cases.

\subsection{Case (UB)}

When the atmosphere is humid and when the boundary layer is absolutely unstable, dry convection in the boundary layer may be a trigger for the initiation of cumulus clouds. In Case (UB) the initial lapse rate below $z \sim 600 \mathrm{~m}$ is taken to be $1 \mathrm{~K} / 100 \mathrm{~m}$, and the initial humidity is slightly modified, as (HC) in Table 1. Other conditions are taken to be the same as those for Case (FC).

As in Case (FC), frictional convergence is not uniform and small-scale irregular motions cause dry convection in the unstable boundary layer. In the present experiment, ten cells are formed in a region $x<20 \mathrm{~km}$, and its spacing is about $2 \mathrm{~km}$, which should be determined from the dynamics of dry convection. The maximum vertical velocities differ from cell to cell and range from 3 to $60 \mathrm{~cm} \cdot \mathrm{sec}^{-1}$ at $90 \mathrm{~min}$. The first cloud is formed at $100 \mathrm{~min}$. At $120 \mathrm{~min}$ we see seven clouds, as shown in Fig. 13. These clouds cause the intensification of large-scale meridional circulation, as in the previous cases. Fig. 14 shows the rainfall intensity. Inward propagations of rainfalls are more notable than in previous cases. 

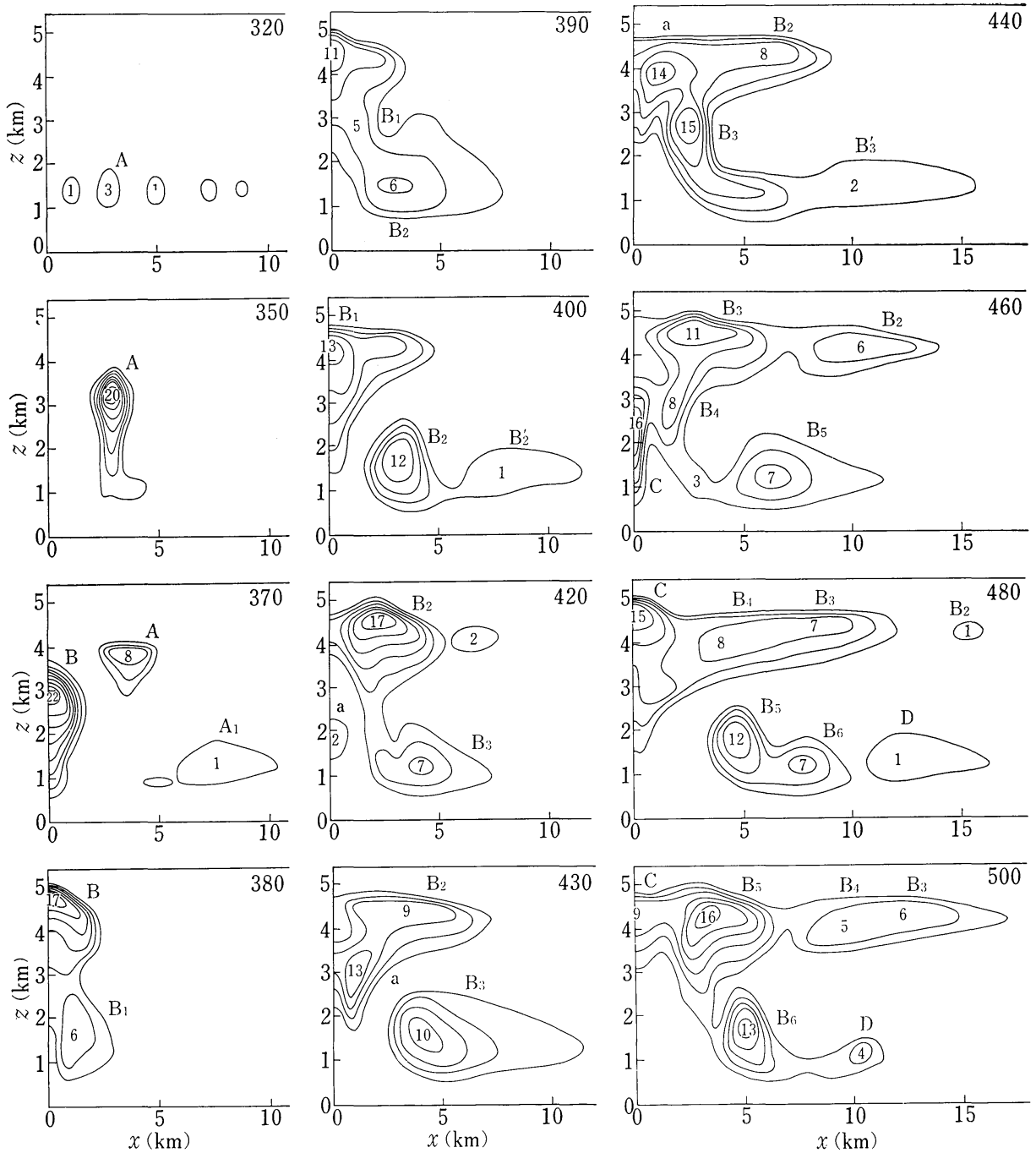

Fig. 11 Vertical cross sections of the cloud water mixing ratio at various times for Case (FC). Extreme values of the mixing ratio in clouds are given in units of $0.1 \mathrm{~g} / \mathrm{kg}$.

The reason for this difference is not clear.

\subsection{Case $(A X)$}

It is more realistic to consider an axial symmetric disturbance rather than a slab symmetric one $(\partial / \partial y=0)$. It is well known that the disturbance becomes stronger in the axial symmetric case. Therefore, it is likely that frictional convergence becomes more important and that TC mode becomes more noticeable. However, when the depth of the conditionally unstable layer is relatively shallow, as in the present experiments, it can be expected that NF mode is still dominant because the disturbance does not become strong enough for TC mode to be dominant. Therefore, the assumption of slab-symmetry is acceptable for qualitative discussions of NF mode.

One numerical experiment has been carried out with the assumption of axial symmetry, other conditions being the same as those for Case (LH). Fig. 15 shows the rainfall intensity. Outward propagations of rainfalls are notably found and rainfalls appear to persist in the outer region. Such a persistent rainfall was also found in Case 2 of Yamasaki (1977b). The time integration is discontinued at $t=9$ hours because convective clouds are formed in the outer region where the horizontal grid sizes are too large to describe 


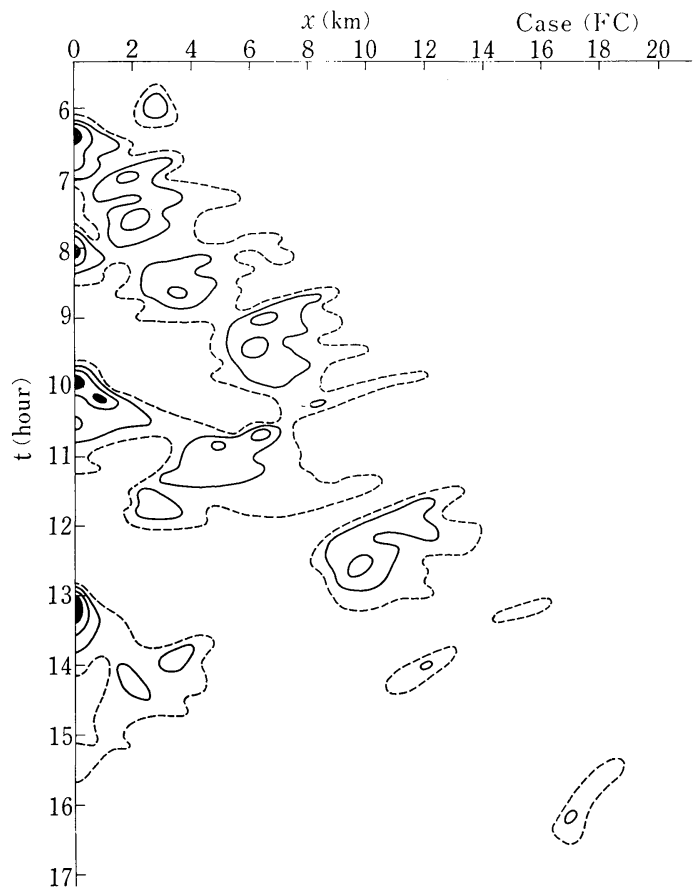

Fig. 12 Rainfall intensity at the surface for Case (FC).

convective clouds properly. The tangential velocity attains $8 \mathrm{~m} \cdot \mathrm{sec}^{-1}$ at this time.

Another numerical experiment has been performed with 'finer' resolution and with a 'drier' initial condition for the 'outer' region. The latter modification is made so as to prevent rainfalls from occuring far from the disturbance center. The integration shows that the initial humidity assumed for the outer region is not high enough for convective clouds to be formed successively after 8 hours. Further numerical experiments with an appropriate initial humidity distribution are required to simulate a disturbance with long life time. However, such numerical experiments have not been attempted.

\section{Other properties of NF mode}

In this section we shall discuss other properties of NF mode. In the following discussions, results obtained from Case (BR) will be presented. Qualitatively the same is true for other cases.

The lower part in Fig. 16 shows the time change of the vertical velocity averaged over the convective area $x<20 \mathrm{~km}$. The solid and dashed lines are the velocities at $z=3.0 \mathrm{~km}$ and $1.2 \mathrm{~km}$, respectively. It can be seen that the order of magnitude of the averaged vertical velocity is
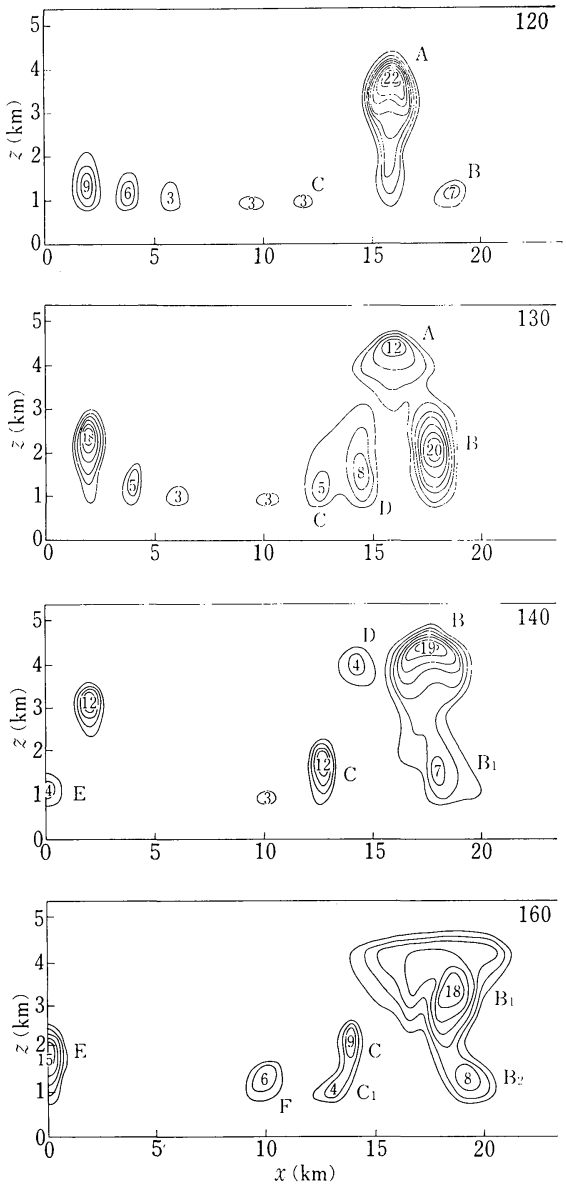

Fig. 13 As in Fig. 11 except for Case (UB).

$10 \mathrm{~cm} \cdot \mathrm{sec}^{-1}$, which corresponds to the horizontal convergence of $10^{-4} \mathrm{sec}^{-1}$. This is comparable to the well-known value observed in the so-called meso-scale disturbance with convective rainfalls in the middle latitudes. This convergence maintains convective activity and vice versa. If the large-scale convergence is of the order of $10^{-5}$ $\sec ^{-1}$, it is improbable that convective activity can be maintained unless convective areas are localized in some parts of the convergence field. This figure also indicates that the averaged vertical velocity oscillates with time. One may say that such an oscillation is due to the fact that the averaged domain includes only a small number of roll-like cumulus clouds. However, it is speculated that the time and/or space variation of the large-scale vertical velocity is one of features of $\mathrm{NF}$ mode even if the averaged domain is large enough to include many clouds or even if we 


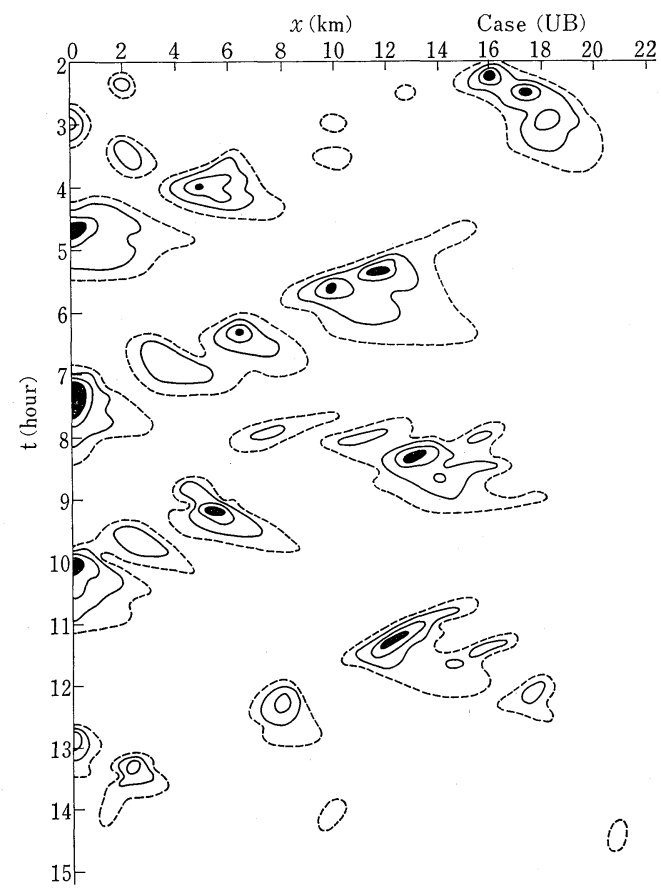

Fig. 14 Rainfall intensity at the surface for Case (UB).

use a three-dimensional model which can describe many clouds of various shapes. When such oscillations exist; in other words, when motions are not quasi-geostrophic, frictional convergence does not occur.

The ageostrophic motions in NF mode can be found more clearly in the upper part of Fig. 16. The dashed line shows the time change of $u$ at

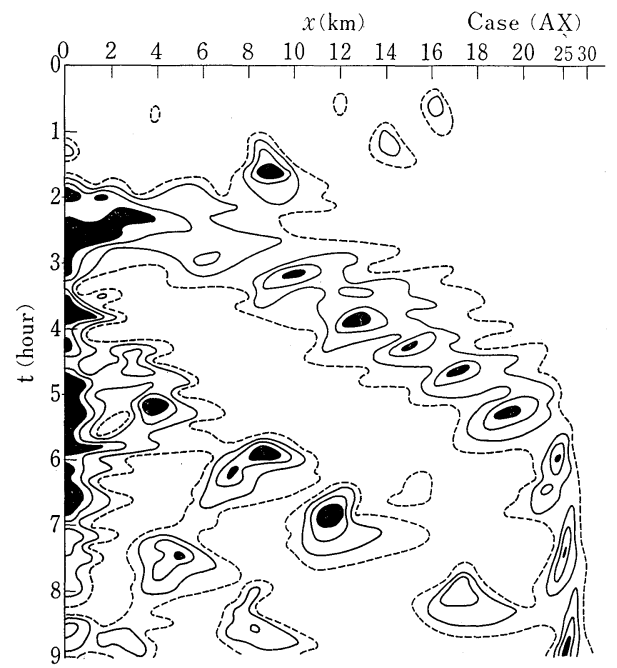

Fig. 15 Rainfall intensity at the surface for Case (AX) which is the axial symmetric case. Abscissa is the radius.

a grid point $(x=30 \mathrm{~km}$ and $z=4 \mathrm{~km}$ ). This is a good measure of the intensity of the outflow in the upper layer. The solid line shows the horizontal pressure gradient force at the same grid point. These two curves show marked oscillations. It can be noted that the intensification of $u$ has a good correspondence to the positive pressure gradient force. The periods of 30 minutes to 1 hour are most noticeable.

The intensification of the meridional circulation is due to the pressure gradient force. The most important term to balance the pressure gradient force is not necessarily the Coriolis force in NF

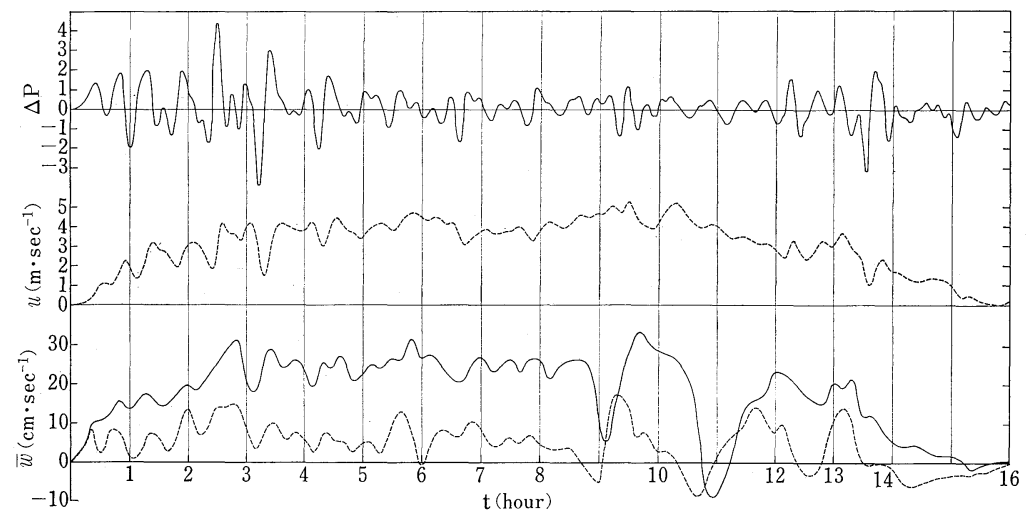

Fig. 16 Time changes of the pressure gradient force (upper solid line) and the $x$-component of the velocity (middle line) at a grid point of $x=30 \mathrm{~km}$ and $z=4 \mathrm{~km}$, and the vertical velocity averaged over the convective area $x \leq 20 \mathrm{~km}$ at $z=3.0 \mathrm{~km}$ (lower solid line) and at $z=1.2 \mathrm{~km}$ (lower dashed line). The unit of the pressure gradient force is $10^{-3} \mathrm{~m} \mathrm{sec}^{-2}$. 

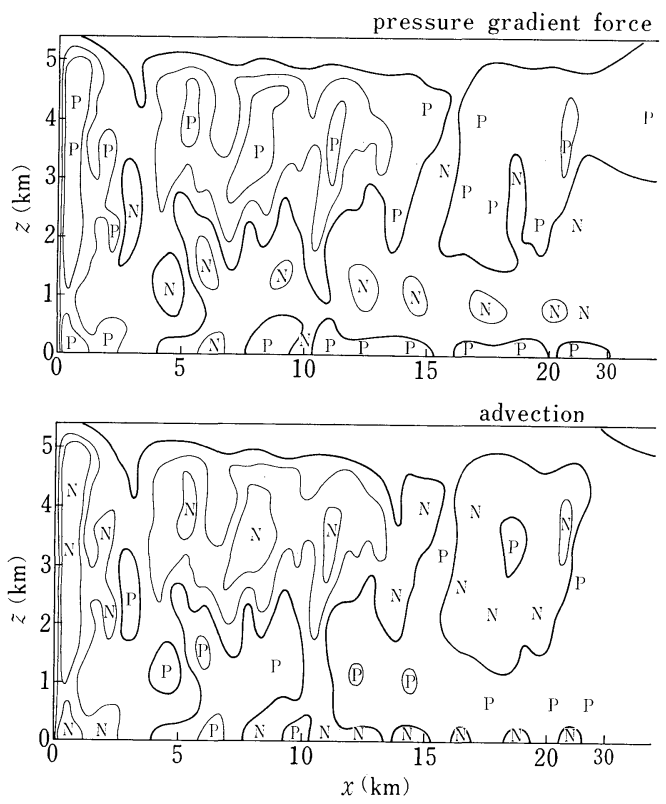

Fig. 17 Vertical cross sections of the pressure gradient force and advection averaged for the first 10 hours. Positive and negative extremes are indicated by $P$ and $N$, respectively.

mode. Except for Case (FC) and (UB) in which the initial state is in quasi-geostrophic balance, the Coriolis force is much smaller than the pressure gradient force in the developing stage. The unimportant role of the Coriolis force is made clear in Case (F). The numerical experiments indicate that the most important term is the advection. The contributions of the advection as well as the pressure gradient force are seen in Fig. 17, which shows the space distributions of these terms averaged over the first 10 hours. The symbols $\boldsymbol{P}$ and $N$ indicate positive and negative extremes, respectively. The most significant result obtained from this figure is that the negative (positive) extremes of the advection are in good correspondence to the positive (negative) extremes of the pressure gradient. The eddy viscosity is not important in most of the domain. It should be remarked, however, that both the advection and the pressure gradient are positive in the upper layer for $x>25 \mathrm{~km}$. In this region, the Coriolis force and the vertical eddy diffusion make negative contributions.

Fig. 18a shows the vertical distributions of the pressure gradient force, advection, Coriolis force and eddy diffusion averaged for $x<20 \mathrm{~km}$ and $t<10$ hours. We see that the advection term is

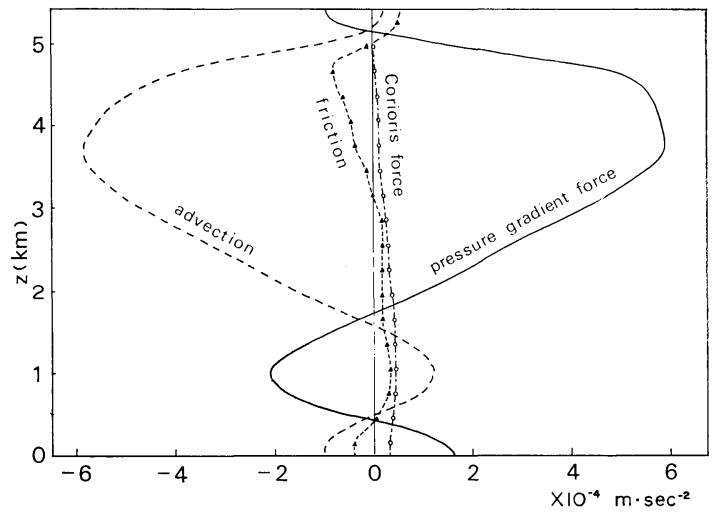

Fig. 18a Vertical profiles of various terms in the equation of motion in the $x$-direction. These are averaged for $x \leq 20 \mathrm{~km}$ and $t \leq 10$ hours.

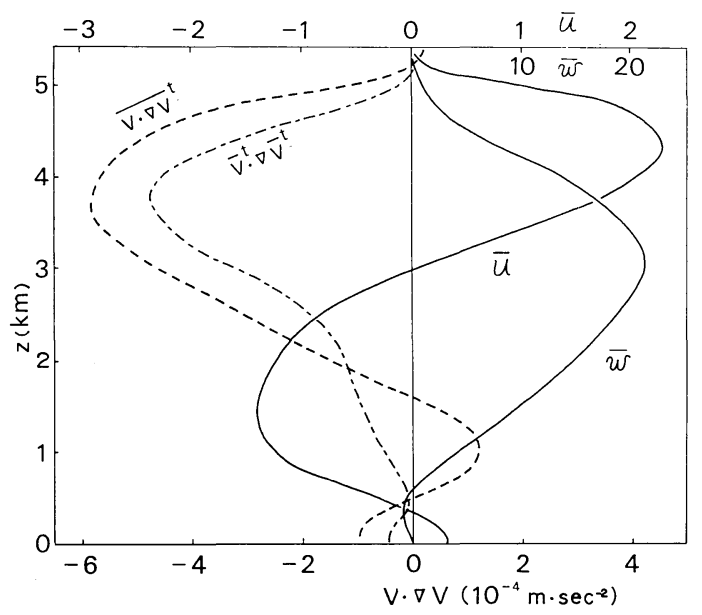

Fig. 18b Vertical profiles of $u, w$ (solid lines) and advection (dashed line) averaged for $x \leq$ $20 \mathrm{~km}$ and $t \leq 10$ hours and $\bar{V} t \cdot \nabla \bar{V}^{t}$ a rough measure of the advection due to large-scale motions (dashed dotted line). The values of $\bar{u}$ and $\bar{w}$ are given in units of $\mathrm{m} \mathrm{sec}^{-1}$ and $\mathrm{cm} \mathrm{sec}^{-1}$, respectively.

nearly balanced with the pressure gradient term, particularly in the upper layer. The small difference between these terms contributes to the intensification of the meridional circulation. Another feature to be noted is that the pressure gradient is directed outward near the surface below $z \sim 400 \mathrm{~m}$. The averaged velocities $\bar{u}$ and $\bar{w}$ are shown by the solid lines in Fig. 18b. We have downward motion below $z \sim 600 \mathrm{~m}$ and outflow below $z \sim 300 \mathrm{~m}$. These features are related with the positive pressure gradient near the surface. 
The dashed line in Fig. $18 \mathrm{~b}$ is the same as the advection curve shown in Fig. 18a. The dashed dotted line shows a rough measure of the largescale advective effect, which is calculated from the time-averaged fields of $u$ and $w$. If the dashed dotted line represents the effect of the large-scale advection even in a quantitative sense, it follows that the difference between these two curves represents the advective effect due to convective motions. It is noteworthy that these two curves have opposite sign in the lower layer. It is certain that convective motions contribute to the increase of $u$ (suppression of inflow) in this layer. It is suggested that the momentum is transported downward by convection and this transport acts to suppress the intensification of the meridional circulation. The former is in agreement with our knowledge concerning the role of convection in a shear flow.

We shall discuss the mechanism of that warming in the inner area of the disturbance which produces the pressure gradient. Fig. 19a shows the vertical distributions of various factors to contribute to the large-scale potential temperature change. These are averaged values over the convective area $x<20 \mathrm{~km}$ and over a period from 4 to 10 hours. The effect of the advection in the thermodynamic equation is divided into the largescale advection and convective effect. The largescale advection is calculated from the timeaveraged fields of the potential temperature and wind. The convective effect is obtained as the difference between the total advection and largescale advection. The solid line and dashed dotted line represent a rough measure of these effects. The following features can be noted from this figure. (1) The effect of the convective transport is one order of magnitude smaller than the net condensation in the middle (and upper) layers. The large-scale cooling is nearly cancelled by latent heat release in cumulus clouds. (2) The convective transport plays an important role in the lower layer, particularly in the subcloud layer where the effect of the evaporation of liquid water is significant. This means that sensible heat is transported downward by convective motions at the cloud base level. This feature was pointed out by Soong and Ogura (1976) for relatively shallow clouds. They also found that the vertical transport acts to counterbalance the evaporative cooling in the uppermost stable layer and that it has negative peaks which correspond to the peaks in condensation heating. (3) A weak secondary peak in the net condensation around

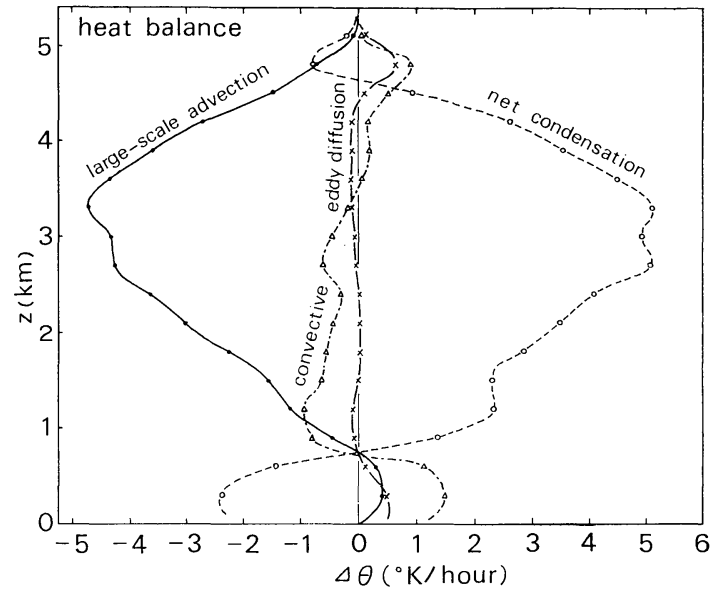

Fig. 19a Vertical profiles of various effects on the time changes of the potential temperature averaged for $x \leq 20 \mathrm{~km}$ and $4 \leq t \leqq 10$ hours.

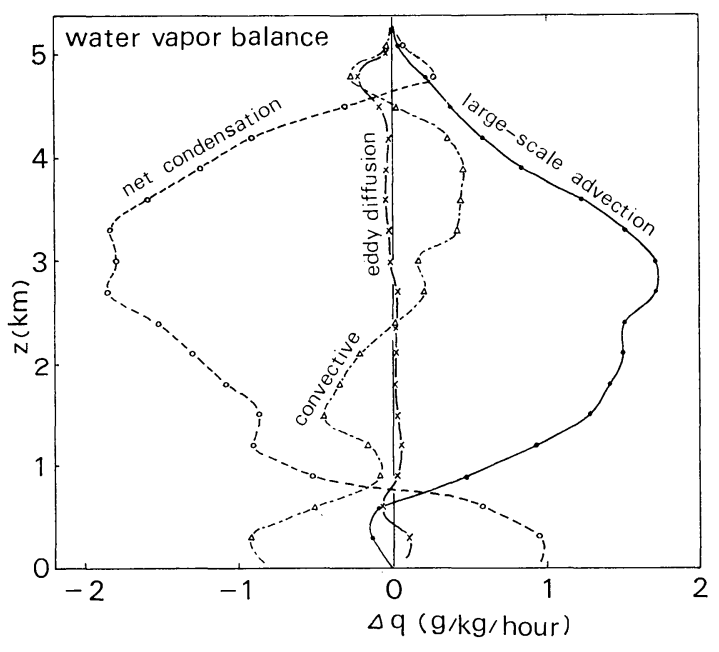

Fig. 19b As in Fig. 19a except for the water vapor mixing ratio.

$z \sim 1.2 \mathrm{~km}$ is related with the result that some of clouds stay at low levels for a relatively long time before ascending (Yamasaki, 1975) and some do not grow into deep cumulus clouds. In other words, bimodal distribution of cumulus clouds, as discussed by Yanai et al. (1973), is simulated in the present experiment for relatively shallow convective layer. (4) Since the large-scale vertical velocity is downward below $z \sim 600 \mathrm{~m}$, as shown before, large-scale advection has a warming effect in this layer. It can be inferred that the largescale downward motion is a result of strong evaporative cooling in the subcloud layer. 


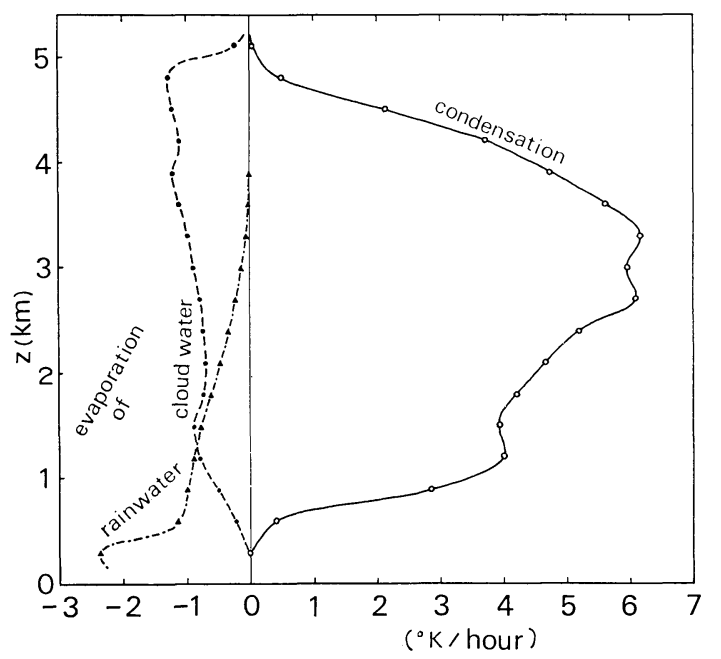

Fig. 20 Vertical profiles of condensation and evaporation of cloud water and rainwater averaged for $x \leq 20 \mathrm{~km}$ and $4 \leq t \leq 10$ hours.

The convective effect is the sum of the net condensation and convective transport. The maximum warming due to convection is located at $z \sim 3.3 \mathrm{~km}$. Although the large-scale potential temperature change is not illustrated in this figure, the height of the maximum warming is also about $3.3 \mathrm{~km}$ (see Fig. 10c in Yamasaki, 1975). The rate of temperature change is less than $0.1 \mathrm{~K} /$ hour, which is much smaller than the temperature change due to the net condensation.

Fig. $19 \mathrm{~b}$ shows the contributions of the largescale advection, convective transport, net condensation and eddy diffusion to the time change of water vapor mixing ratio. We see the following features: (1) The effect of the convective transport is not very small compared with the net condensation except in the middle layer. (2) In the subcloud layer the moistening effect of the evaporation of liquid water is nearly compensated by the drying effect of the convective transport. (3) Two peaks of the drying effect of the convective transport can be found in the subcloud layer and in the lower levels of the cloud layer. This feature was also obtained by Soong and Ogura (1976) for relatively high clouds. (4) In contrast to their results, the drying effect due to transport reaches a relatively high level $(z \sim$ $2.4 \mathrm{~km}$ ). This means that high clouds are dominant in the present case.

The net condensation in Fig. 19a consists of three components; actual condensation, evaporation of cloud water and evaporation of rainwater.

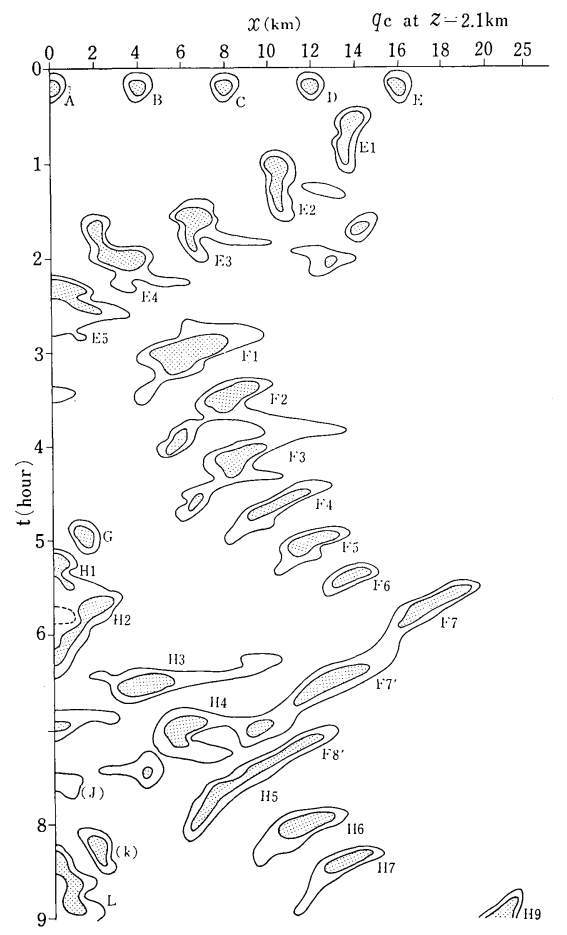

Fig. 21a Cloud water mixing ratio at a height of $2.1 \mathrm{~km}$ as a function of $x$ and $t$. Mixing ratio larger than $0.5 \mathrm{~g} / \mathrm{kg}$ is indicated by shade.

The vertical distributions of these quantities are shown in Fig. 20. As expected, evaporation (cooling and moistening) of cloud water is largest at upper levels (cloud top) and that of rainwater is largest near the surface. It should also be remarked that evaporation of cloud water takes a weak secondary peak at lower levels $(z \sim 1.5 \mathrm{~km})$. This is related with shallow clouds.

Finally we shall discuss some properties of individual cumulus clouds. As already shown, cumulus clouds in NF mode are not formed randomly, but rather systematically. In particular, new clouds are generally formed outward from old clouds. Thus outward propagations of rainfall area are clearly found. As an example, for the first 9 hours in Case (BR), we shall see how clouds are formed. Figs. 21a and 21b show the $x$ - $t$ diagrams of cloud water mixing ratio at $z=$ $2.1 \mathrm{~km}$ and $0.9 \mathrm{~km}$, respectively. Clouds which give rise to appreciable rainfalls (Fig. 8) are named. The following features may be noted from these figures and Fig. 8. (1) The outward propagation speed of rainfall area due to cloud systems $F$ and $H$ is $0.7 \sim 1.5 \mathrm{~m} \cdot \mathrm{sec}^{-1}$. New cumulus clouds are formed every about 30 


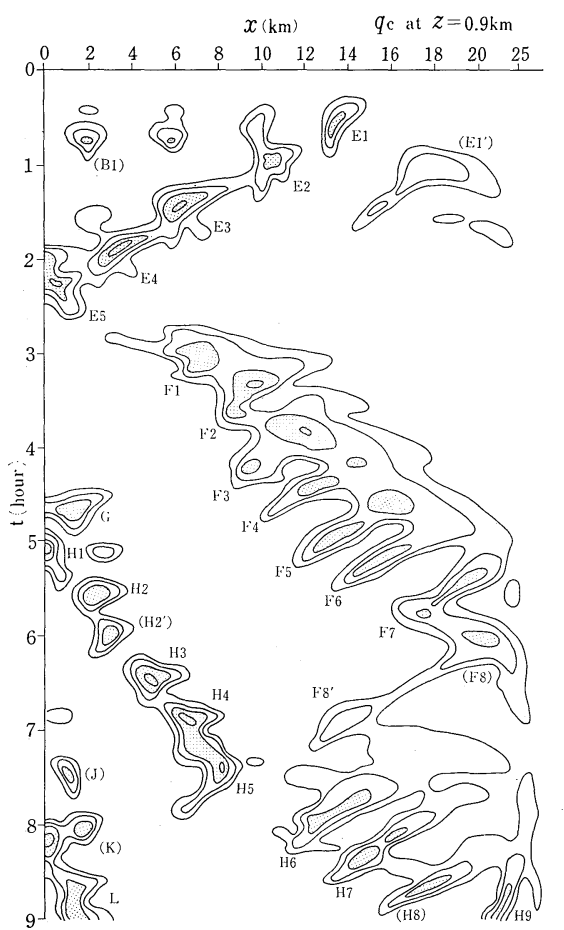

Fig. 21b Cloud water mixing ratio at $0.9 \mathrm{~km}$. Contours are $0.2 \mathrm{~g} / \mathrm{kg}$ intervals. Mixing ratio larger than $0.4 \mathrm{~g} / \mathrm{kg}$ is shaded.

minutes, about $2 \mathrm{~km}$ outward from the location of older cloud formation. Cumulus clouds move inward mainly because of low-level wind. This direction is in opposition to the propagation direction of the systems. The inward shift of individual rainfalls (Fig. 8) is due to such cloud movement. The effect of the inward advection of rainwater by low-level wind is small. In contrast to systems $F$ and $H$, new clouds are formed inward from old clouds in the case of system $E$. This feature is also seen for clouds $\mathrm{F}^{\prime}$ and $\mathrm{F}^{\prime}$. In the former case, the inward propagation may be related with the initial condition under which the most intense cloud $E$ is formed in the outer part of the convective area. Individual rainfalls shift outward in this case (Fig. 8). (2) The large-scale convergence produces stratiform clouds at low levels in the outer region. That is, the horizontal scale of low-level clouds is generally large. The inner part of this cloud is separated from the outer part and moves inward. After staying at low levels for a relatively long time it starts to grow into cumulus cloud and go upward. On the other hand, the horizontal scale of clouds in the inner region is generally small and clouds ascends soon

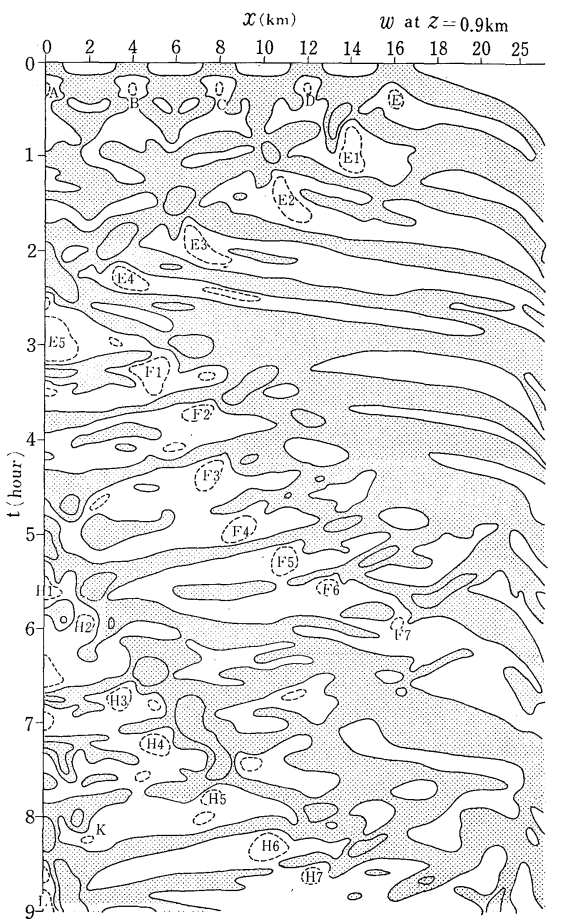

Fig. 21c Vertical velocity at $0.9 \mathrm{~km}$. Upward motions are shaded. The solid lines are drawn for $w=0$ and $1 \mathrm{~m} \mathrm{sec}-1$ and the dashed lines are for $w=$ $-1 \mathrm{~m} \mathrm{sec}^{-1}$.

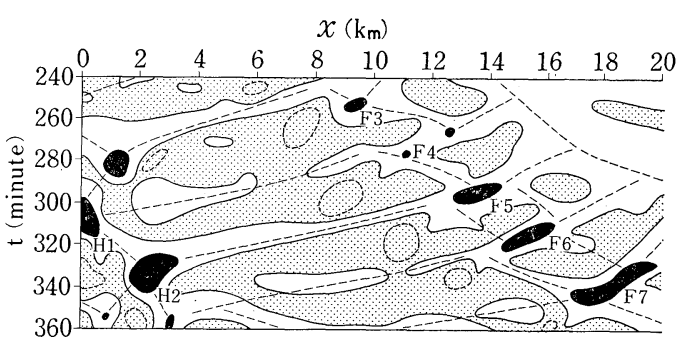

Fig. 21d Vertical velocity at $0.9 \mathrm{~km}$ from $240 \mathrm{~min}$ to $360 \mathrm{~min}$. Dashed lines indicate propagations of upward motions associated with gravity waves. The black areas mean that vertical velocity exceeds $1 \mathrm{~m} \cdot \mathrm{sec}^{-1}$ and dotted lines mean that it is less than $-1 \mathrm{~m} \cdot \mathrm{sec}^{-1}$. In contrast to Fig. $21 \mathrm{c}$, downward motions are shaded.

after their formation. At the middle level $(z \sim$ $2.1 \mathrm{~km}$ ) the horizontal scale is $1.5 \sim 2.5 \mathrm{~km}$ in most cases.

Fig. 21c shows the vertical velocity at $z=$ $0.9 \mathrm{~km}$. Concerning systems $F$ and $H$, the downdraft due to rainwater forms to the left of the major updraft because clouds move to the left 
(about $3 \mathrm{~km}$ ) while ascending. Afterwards, there exist two propagations of upward motion areas; one is leftward and the other is rightward. This rightward upward motion interacts with another upward motion associated with 'gravity waves' which propagate from the right (with a phase velocity of $2 \sim 5 \mathrm{~m} \cdot \mathrm{sec}^{-1}$ ). When the phases of these two vertical motions coincide, upward motion is intensified and a new cumulus cloud is formed. The downdraft associated with the old cloud plays an important role to maintain the updraft which is responsible for cloud formation. Such an important role of the downdraft and gravity waves was pointed out by Takeda (1971). This figure clearly demonstrates the role of gravity waves. Part of Fig. 21c is shown in Fig. 21d which is illustrated to see the behaviors of gravity waves more clearly. Pronounced propagations of gravity waves are indicated by dashed lines. In contrast to Fig. 21c, downward motions are shaded and names F3, F4, . . are given to major updrafts. Corresponding downdrafts which are found to the lower left of the updrafts are indicated by dotted lines.

In order to see the mechanism of cloud formation and evolution more clearly, vertical cross sections of various fields at five consecutive times are presented. The solid and dashed lines in Fig. 22a indicate cloud water and rainwater mixing ratios, respectively. Fig. $22 \mathrm{~b}$ shows the vertical motion field. The axis of low and high pressure are also shown by the double solid and dashed lines. The potential temperature anomaly is shown in Fig. 22c.

At $t=270 \mathrm{~min}$ cloud $\mathrm{F} 4$ is growing from part of the low-level stratiform cloud and the downdraft is already formed. It is noteworthy that the downdraft is located on the 'right' side below the updraft. This is because the cloud is moving leftward and because the downdraft is caused by rainwater. Cloud F3 is at the decaying stage and its downdraft is located just below the updraft. At $t=280 \mathrm{~min}$ the downdraft associated with cloud F4 has the same feature. Upward motion at low levels is separated on both sides of the downdraft. The left one propagates leftward and contributes to create cloud $H 1$ (Fig. 21d). The right one propagates rightward. Another upward motion area exists around $x=17 \mathrm{~km}$. This ascending area propagates leftward. At $t=290 \mathrm{~min}$ when these two upward motions are in phase, cloud F5 begins to grow. The downdraft associated with F4 plays an important role in this growth. At $t=300 \mathrm{~min}$ the downdraft forms on
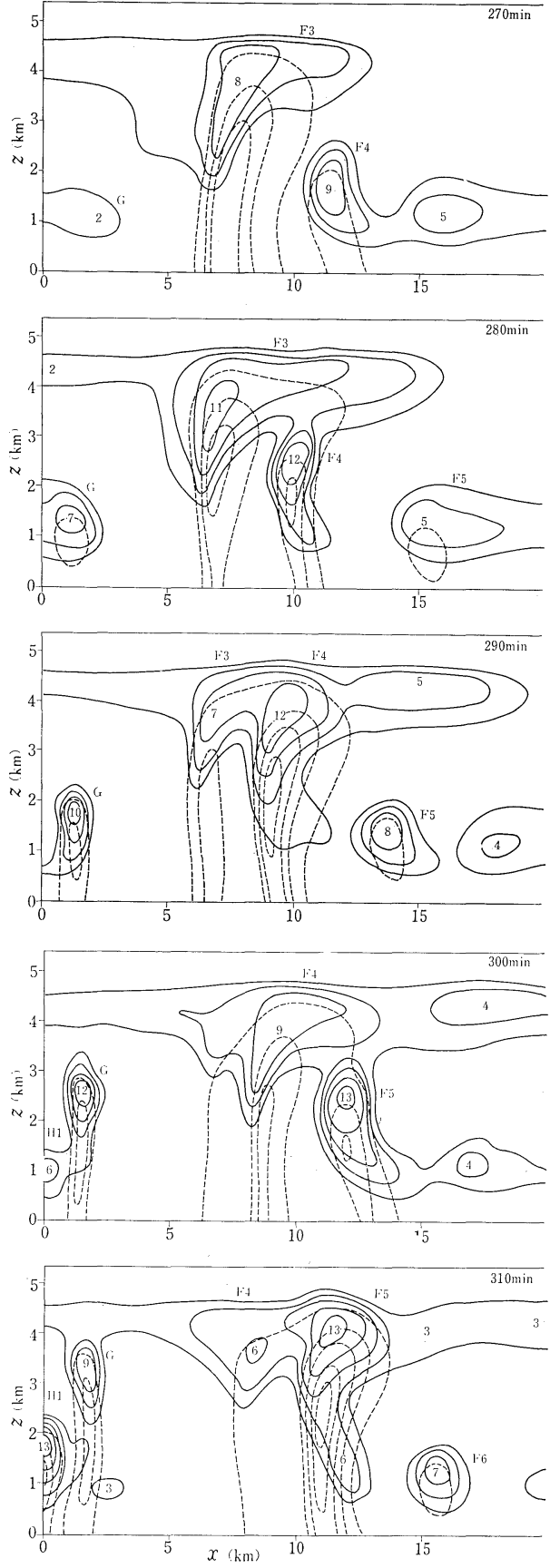

Fig. 22a Vertical cross sections of the cloud water mixing ratio (solid lines) and the rainwater mixing ratio (dashed lines). Extreme values of cloud water are indicated by numerals in units of $0.1 \mathrm{~g} / \mathrm{kg}$. The dashed lines are drawn for $q_{r}=0.1,0.5,1.0,2.0$ and $3.0 \mathrm{~g} / \mathrm{kg}$. 

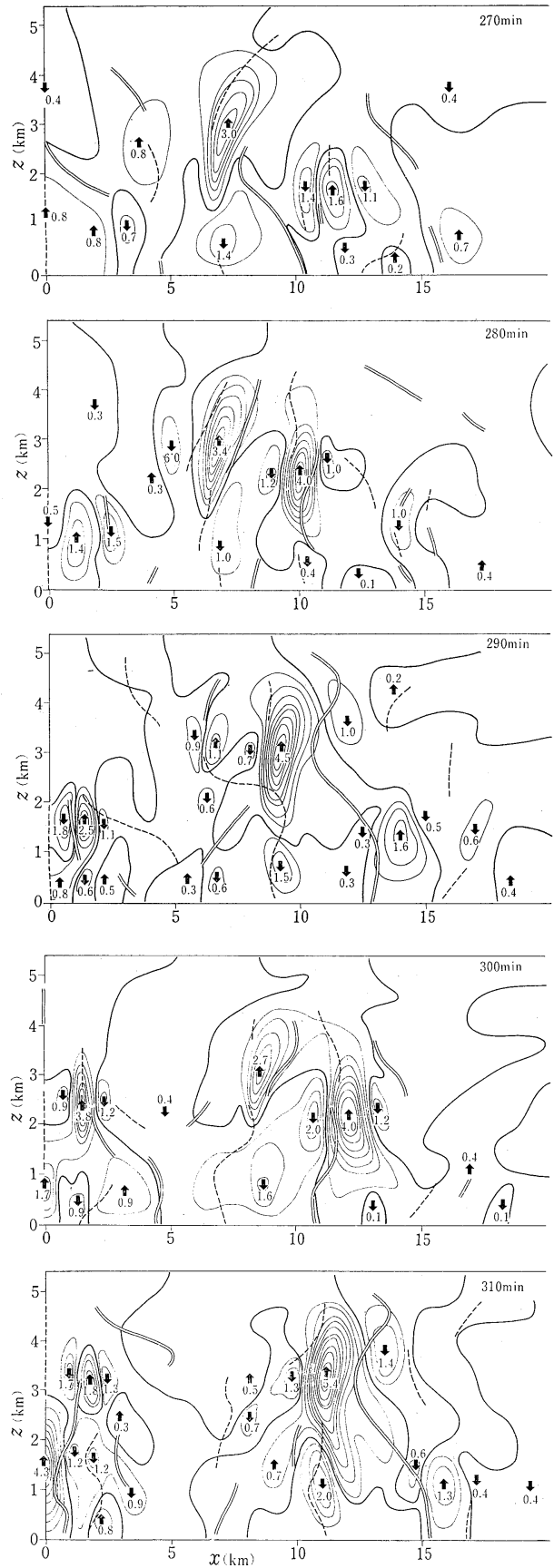

Fig. 22b Vertical cross sections of the vertical velocity. Extreme values and their positions are shown by numerals $\left(\mathrm{m} \mathrm{sec}^{-1}\right)$ and arrows. Contour interval is $0.5 \mathrm{~m}$ $\mathrm{sec}^{-1}$. The double solid and dashed lines indicate low and high pressure axes, respectively.
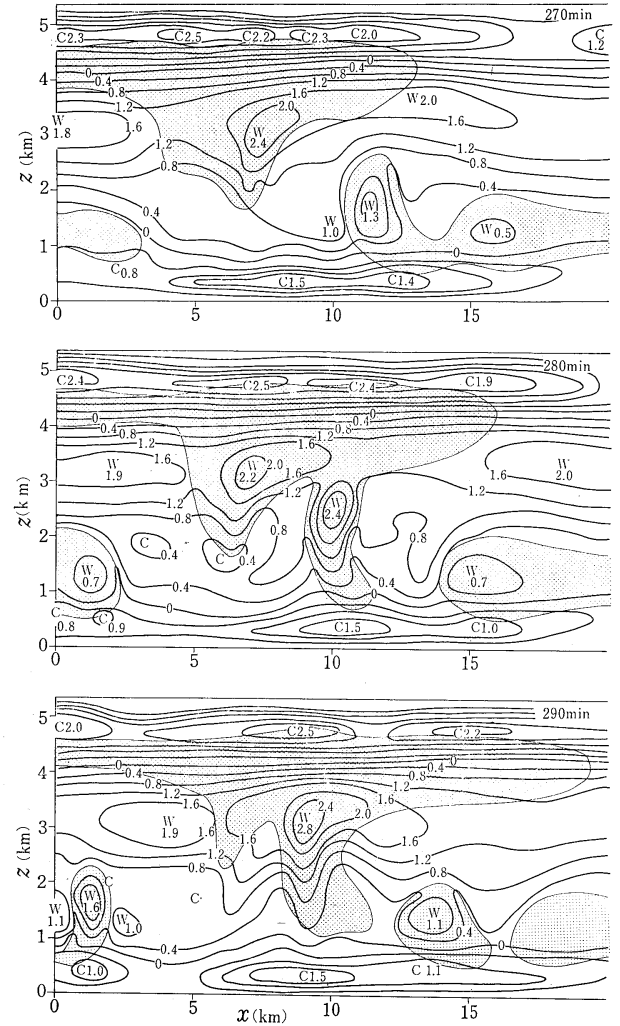

Fig. 22c Vertical cross sections of the potential temperature anomaly (K). Positive and negative extremes are indicated by $W$ and $C$, respectively. Negative sign referred to $C$ is omitted. Cloud areas are shaded.

the right side below the updraft, as in the previous case. The middle-level compensating downward motion of cloud F5 and the low-level downdraft of cloud F4 forms a large area of downward motions. This feature was also found at $t=280$ min. Cloud F6 starts to grow at $t=310 \mathrm{~min}$ in the same mechanism as F5. The left part of upward motion divided by the downdraft of F5 propagates leftward and contributes to create cloud $H 2$ (Fig. 21d).

As for the pressure field, a low pressure axis is found around the left edge of the ascending area of leftward propagating gravity wave $(t=$ $280 \mathrm{~min}$ ). When cumulus cloud begins to grow, this axis becomes pronounced and extends upward to the right side of the upper-level old cloud ( $t=$ 270,290 and $310 \mathrm{~min}$ ). The phase difference between the pressure and vertical motion at low levels is related with the inward shift of these fields. A high pressure axis is found in the upper part of growing and mature clouds and also in 
the downdraft area with appreciable rainfall near the surface. At the dissipating stage of the downdraft, this axis shifts leftward relative to the downdraft $(t=280$ and $300 \mathrm{~min})$. Although the phase of the vertical motion propagates in both direction, only the leftward phase propagation is noticeable in the surface pressure field.

As is well known, the rain area is relatively cold near the surface. This cooling is produced by the upward motion which occurs in the growing stage before rainfall and, to a less extent, by the evaporation of rainwater. When the downdraft develops, the temperature begins to rise because the evaporative cooling is generally smaller than the adiabatic warming. The importance of the evaporative cooling is clear in the heat budget for the whole domain (Fig. 19a).

\section{Concluding remarks}

In this paper we have discussed some properties of a CISK mode whose instability is not essentially affected by surface friction. Since surface friction plays an important role in strong disturbances such as tropical cyclones, the CISK of this type can be applied to weak disturbances in which the relative vorticity is too small to cause significant frictional convergence. The small or negligible effect of surface friction is also found in the so-called Wave-CISK. In this case the $\beta$ effect is essential so that the Wave-CISK theory can be applied only to long waves whose wavelength is larger than several thousand kilometers. The CISK treated in this study (NF mode) is applicable to relatively small-scale disturbances in which the horizontal scale of the ascending area (convective area) is less than several hundred kilometers. In this study the horizontal scale of the convective area is chosen as several tens of kilometers partly because of computational limitations. However, the results obtained may be true for larger disturbances in the qualitative sense. The most typical example of NF mode in the actual atmosphere may be tropical depression and weak tropical cyclones at the formative and early developing stages. Although most of easterly waves are probably caused by CISK of different types to which the vertical shear of the easterlies and/or $\beta$-effect are indispensable, some may be explained as NF mode. Some of cloud clusters in the tropics may also belong to this category. In the middle latitudes, meso-scale convective systems are often observed. Many of them behave like gravity waves, particularly under strong vertical shear of the prevailing wind. However, it is probable that NF mode becomes significant in some cases. These speculations may not be appropriate to be made at the present time. In order to discuss this problem, further theoretical and observational studies are required. It should be, however, remarked that the unimportant role of surface friction in weak tropical disturbances has been increasingly recognized in recent years.

As mentioned above, the horizontal scale of the ascending area in NF mode probably takes a wide range from several ten to several hundred kilometers. The scale realized at the mature stage should strongly depend on the initial condition, particularly on the horizontal scales of humid area and of the initial ascending motion which is caused for some reason. Another property of NF mode is that the horizontal scale of the ascending area tends to increase with time if the humid area is sufficiently wide because new clouds may be successively formed outward from old clouds. As for the time scale of NF mode, the time required for the realization of nearly neutral stratification near the disturbance center is a good measure. This also depends on the initial condition. In contrast to TC mode in which a quasi-steady state is possible to be realized (Yamasaki, 1977a, b), the life time of NF mode is probably finite in any case. Although it is not clear why such difference is found, the following remarks may help us understand this problem. In the case of TC mode, large-scale upward motions in the eyewall area are maintained by frictional convergence as well as the pressure gradient force. Therefore, the conditionally unstable stratification is maintained by the destabilizing effect of the forced vertical motion against the stabilizing effect of convective clouds. On the other hand, upward motions in NF mode are maintained only by the pressure gradient force. When the stratification near the disturbance center approaches a neutral state, the pressure gradient becomes small because of adiabatic warming in the large-scale descending region. Therefore, upward motions are not maintained.

The horizontal convergence in NF mode is of the order of $10^{-4} \mathrm{sec}^{-1}$ in the present experiment. This magnitude of convergence is considered to be necessary to maintain convective activity. When we consider a larger-scale NF mode, there is a possibility that convective activity should not be uniform in the large-scale ascending area but localized in some regions. If this is the case and if the convergence associated with individual organized convective systems is of the 
order of $10^{-4} \mathrm{sec}^{-1}$, NF mode has smaller magnitude of convergence such as $10^{-5} \mathrm{sec}^{-1}$. In other words, if the large-scale convergence is $10^{-5}$ $\mathrm{sec}^{-1}$, convective activity should be localized in some regions in order that the large-scale disturbance may develop. It remains for future studies to simulate such weak NF mode if it exists.

In this study stationary (relative to basic flow) CISK mode has been treated. As mentioned in section 1 , it is possible that there exists a propagating CISK mode which may behave like gravity waves. The appearance of such a mode is precluded in the present experiment because we adopt an assumption that the disturbance is symmetric with respect to $x=0$. In connection with the symmetric assumption, the following remarks should be made. An additional numerical experiment has been performed by removing this assumption, other conditions being the same as those for Case (LH). As far as small-scale convective motions are concerned, the symmetry with respect to $x=0$ is gradually lost as time goes on. However, the symmetry of the large-scale feature is fairly maintained for a long time. This means that the symmetric CISK mode is not unstable with respect to asymmetric mode. Which mode becomes dominant is probably dependent on the initial condition. A propagating CISK mode may be simulated if the initial condition is highly asymmetric. In addition, the vertical shear of the prevailing wind may be one of necessary conditions for a propagating CISK mode. Numerical experiments on such a CISK mode require much computational time and remain to be made in the future.

\section{References}

Anthes, R. A., 1972: Development of asymmetries in a three-dimensional numerical model of the tropical cyclone. Mon. Wea. Rev., 100, 461-476.

- S. L. Rosenthal and J.W. Trout, 1971: Preliminary results from an asymmetric model of the tropical cyclone. Mon. Wea. Rev., 99, 744758.

Arakawa, A., and W. H. Schubert, 1974: Interaction of a cumulus cloud ensemble with the largescale environment. Part I. J. Atmos. Sci., 31, 674-701.

Berry, E.X., 1968: Modification of the warm rain process. Proceedings of the first national conference on weather modification, 1968, Amer. Met. Soc., Boston, Mass., 81-85.

Chang, C.-P., and R.T. Williams, 1974: On the short-wave cutoff of CISK. J. Atmos. Sci., 31, 830-833.
Charney, J., and A. Eliassen, 1964: On the growth of the hurricane depression. J. Atmos. Sci., 21, 68-75.

Gambo, K., 1976: The instability of medium-scale disturbances in a moist atmosphere. J. Met. Soc. Japan, 54, 191-207.

Hayashi, Y., 1970: A theory of large-scale equatorial waves generated by condensation heat and accelerating the zonal wind. J. Met. Soc. Japan, 48, 140-160.

- 1971: Large-scale equatorial waves destabilized by convective heating in the presence of surface friction. J. Met. Soc. Japan, 49, 458466.

Kessler, E., 1969: On the distribution and continuity of water substance in atmospheric circulation. Met. Monogr., 10, No. 32, 84 pp.

Kurihara, Y., and R. E. Tuleya, 1974: Structure of a tropical cyclone developed in a three-dimensional numerical simulation model. J. Atmos. Sci., 31, 893-919.

Lindzen, R. S., 1974: Wave-CISK in the tropics. J. Atmos. Sci., 31, 156-179.

Mathur, M. B., 1975: Development of banded structure in a numerically simulated hurricane. $J$. Atmos. Sci., 32, 512-522.

Matsumoto, S., and K. Ninomiya, 1969: On the role of convective momentum exchange in the mesoscale gravity wave. J. Met. Soc. Japan, 47, 7585.

Matsuno, T., 1966: Quasi-geostrophic motions in the equatorial area. J. Met. Soc. Japan, 44, 25-43.

Murakami, T., 1972: Balance model in a conditionally unstable tropical atmosphere. J. Atmos. Sci., 29, 463-487.

Murray, F. W., and L. R. Koenig, 1972: Numerical experiments on the relation between microphysics and dynamics in cumulus convection. Mon. Wea. Rev., 100, 717-732.

Ogura, Y., 1964: Frictionally controlled, thermally driven circulations in a circular vortex with application to tropical cyclones. J. Atmos. Sci., 21, 610-621.

-, and T. Takahashi, 1971: Numerical simulation of the life cycle of a thunderstorm cell. Mon. Wea. Rev., 99, 895-911.

Ooyama, K., 1964: A dynamical model for the study of tropical cyclone development. Geofisica Internacional (Mexico), 4, 187-198.

- 1969: Numerical simulation of the life cycle of tropical cyclones. J. Atmos. Sci., 26, 3-40.

Rosenthal, S. L., and W. J. Koss, 1968: Linear analysis of a tropical cyclone model with increased vertical resolution. Mon. Wea. Rev., 96, 858-868.

Soong, S.-T., and Y. Ogura, 1976: A determination of the trade-wind cumuli population using BOMEX data and an axisymmetric cloud model. 
J. Atmos. Sci., 33, 992-1007.

Stark, T.E., 1976: Wave-CISK and cumulus parameterization. J. Atmos. Sci., 33, 2383-2391.

Sundqvist, H., 1970a: Numerical simulation of the development of tropical cyclones with a ten-level model. Part I. Tellus, 22, 359-390.

- $1970 \mathrm{~b}$ : Numerical simulation of the development of tropical cyclones with a ten-level model. Part II. Tellus, 22, 504-510.

Syono, S., and M. Yamasaki, 1966: Stability of symmetrical motions driven by latent heat released by cumulus convection under the existence of surface friction. J. Met. Soc. Japan, 44, 353375.

Takeda, T., 1971: Numerical simulation of a precipitating convective cloud: the formation of a "long-lasting" cloud. J. Atmos. Sci., 28, 350376.

Tokioka, T., 1973: A stability study of mediumscale disturbances with inclusion of convective effects. J. Met. Soc. Japan, 51, 1-10.

Wada, M., 1977: The properties of Typhoon-scale disturbances produced by Arakawa-Schubert parameterization. J. Met. Soc. Japan, 55, 364391.

Wilhelmson, R., and Y. Ogura, 1972: The pressure perturbation and the numerical modelling of a cloud. J. Atmos. Sci., 29, 1295-1307.
Yamasaki, M., 1968: Detailed analysis of a tropical cyclone simulated with a 13-layer model. Pap. Met. Geophys., 19, 559-585.

, 1969: Large-scale disturbances in the conditionally unstable atmosphere in low latitudes. Pap. Met. Geophys., 20, 289-336. 1971: A further study of wave disturbances in the conditionally unstable model tropics. J. Met. Soc. Japan, 49, 391-415.

- 1975: A numerical experiment of the interaction between cumulus convection and larger-scale motion. Pap. Met. Geophys., 26, 63-91.

, 1977a: A preliminary experiment of the tropical cyclone without parameterizing the effects of cumulus convection. J. Met. Soc. Japan, 55, 11-31.

, 1977b: The role of surface friction in tropical cyclones. J. Met. Soc. Japan, 55, 559572.

Yanai, M., and T. Maruyama, 1966: Stratospheric wave disturbances propagating over the equatorial Pacific. J. Met. Soc. Japan, 44, 291-294.

, S. Esbensen, and J.-H. Chu, 1973: Determination of bulk properties of tropical cloud clusters from large-scale heat and moisture budgets. J. Atmos. Sci., 30, 611-627.

\title{
地表摩擦の影響をうけない CISK モードについて
}

\author{
山 岬 正 紀 \\ 気象研究所
}

前論文（山岬，1975）の続きとして，地表摩擦によって本質的に影響をうけないタイプの CISK モードの性質を 調べるため，種々のパラメーターや初期条件を変えて数值実験を行なった。用いた方程式系は雲水量・雨水量に対す る式を含み, 雲物理過程はパラメタライズしてある。対流活動が起る CISK じょう乱の中心域では, 個々の積雲の 振舞いを妥当に記述しらるように水平方向 $200 \mathrm{~m}$ の格子間隔を用いた。ただしモデルは 2 次元モデルでありまた 計算時間の節約のため, 対流活動が数十 $\mathrm{km}$ 程度の小さな領域に限られるよらに初期条件を選んだ。対流との相互作 用によって発達するじょら乱の渦度が大きくなって地表摩擦が重要な役割を果すことにならないように, 条件付不安 定層の厚さが比較的浅い大気成層の状態を扱っている。

数值実験の結果によれば，このような CISK モードでは，気圧傾度力と移流項とが水平方向の運動方程式の項の 中で重要であり, コリオリカはじょら乱の発達の速さや構造をいく分变える程度の役割をもつが不安定性に対して本 質的ではない。対流活動による昇温によってつくられる気圧傾度からは子午面循環の急速な強まりが期待されるが， 対流による運動量輸送がこれを抑えるように働らき,じょう乱のゆっくりとした発達をもたらしている。対流活動域 での雨の降り方はランダムではなくある程度規則的であり, 特に, じょう乱の中心から外の方向への伝播が顕著であ る。雲水から雨水への变換が起らないと仮定すると, 数多くの積雲の指続的発生は見られず CISK は維持されな い。即ち, 雨水の蒸発とひきずり力は，ここで扱っている CISK モードに拈いて本質的であり，大規模収束がない ときの新しい積雲の発生の場合と同様重要な役割を果している。

個々の積雲の振舞い，持続的発生の様子，大規模場の熱と水蒸気の収支に対する積雲の集団的効果についても調べ た。 